\title{
Storage and stability of organic carbon in soils as related to depth, occlusion within aggregates, and attachment to minerals
}

\author{
M. Schrumpf ${ }^{1}$, K. Kaiser ${ }^{2}$, G. Guggenberger ${ }^{3}$, T. Persson ${ }^{4}$, I. Kögel-Knabner ${ }^{5}$, and E.-D. Schulze ${ }^{1}$ \\ ${ }^{1}$ Max Planck Institute for Biogeochemistry, Hans-Knöll-Straße 10, 07745 Jena, Germany \\ ${ }^{2}$ Soil Sciences, Martin Luther University Halle-Wittenberg, Weidenplan 14, 06108 Halle, Germany \\ ${ }^{3}$ Institute of Soil Science, Leibniz Universität Hannover, Herrenhäuser Straße 2, 30419 Hanover, Germany \\ ${ }^{4}$ Department of Ecology, Swedish University of Agricultural Sciences, P.O. Box 7044, 75007 Uppsala, Sweden \\ ${ }^{5}$ Chair of Soil Science, Technische Universität München, Department for Ecology and Ecosystem Management, \\ Emil-Ramann-Straße 2, 85354 Freising, Germany
}

Correspondence to: M. Schrumpf (mschrumpf@bgc-jena.mpg.de)

Received: 2 August 2012 - Published in Biogeosciences Discuss.: 21 September 2012

Revised: 21 February 2013 - Accepted: 22 February 2013 - Published: 13 March 2013

\begin{abstract}
Conceptual models suggest that stability of organic carbon (OC) in soil depends on the source of plant litter, occlusion within aggregates, incorporation in organomineral complexes, and location within the soil profile. Density fractionation is a useful tool to study the relevance of OC stabilization in aggregates and in association with minerals, but it has rarely been applied to full soil profiles. We aim to determine factors shaping the depth profiles of physically unprotected and mineral associated OC and test their relevance for OC stability across a range of European soils that vary in vegetation, soil types, parent material, and land use. At each of the 12 study sites, 10 soil cores were sampled to $60 \mathrm{~cm}$ depth and subjected to density separation. Bulk soil samples and density fractions (free light fractions - fLF, occluded light fractions - oLF, heavy fractions - HF) were analysed for $\mathrm{OC}$, total nitrogen (TN), $\delta^{13} \mathrm{C}$, and $\Delta^{14} \mathrm{C}$. Bulk samples were also incubated to determine $\mathrm{CO}_{2}$ evolution per $\mathrm{g}$ OC in the samples (specific mineralization rates) as an indicator for OC stability.

Depth profiles of OC in the light fraction (LF-OC) matched those of roots for undisturbed grassland and forest sites, suggesting that roots are shaping the depth distribution of LF-OC. Organic C in the HF declined less with soil depth than LF-OC and roots, especially at grassland sites. The decrease in $\Delta^{14} \mathrm{C}$ (increase in age) of HF-OC with soil depth was related to soil $\mathrm{pH}$ as well as to dissolved $\mathrm{OC}$ fluxes. This indicates that dissolved $\mathrm{OC}$ translocation contributes to the formation of subsoil HF-OC and shapes the $\Delta^{14} \mathrm{C}$ profiles.
\end{abstract}

The LF at three sites were rather depleted in ${ }^{14} \mathrm{C}$, indicating the presence of fossil material such as coal and lignite, probably inherited from the parent material. At the other sites, modern $\Delta{ }^{14} \mathrm{C}$ signatures and positive correlations between specific mineralization rates and fLF-OC indicate the fLF is a potentially available energy and nutrient source for subsurface microorganisms throughout the profile. Declining specific mineralization rates with soil depth confirm greater stability of OC in subsoils across sites. The overall importance of OC stabilization by binding to minerals was demonstrated by declining specific mineralization rates with increasing contributions of HF-OC to bulk soil OC, and the low $\Delta^{14} \mathrm{C}$ values of HF-OC. The stability of HF-OC was greater in subsoils than in topsoils; nevertheless, a portion of HF-OC was active throughout the profile. While quantitatively less important than OC in the HF, consistent older ages of oLF-OC than fLF-OC suggest that occlusion of LF$\mathrm{OC}$ in aggregates also contributes to OC stability in subsoils. Overall, our results indicate that association with minerals is the most important factor in stabilization of OC in soils, irrespective of vegetation, soil type, and land use.

\section{Introduction}

The response of soil organic matter $(\mathrm{OM})$ to environmental changes is determined by mechanisms regulating its turnover at different spatial and temporal scales. Early research 
evidenced that not all organic carbon (OC) in soils is equally decomposable and that modelling its dynamics requires considering more than one OM pool (Gärdenäs et al., 2011). Many soil models are based on the idea of OC stability and turnover being determined by the complexity of organic molecular structures (Gärdenäs et al., 2011; Peltoniemi et al., 2007). However, because all OM in soil is potentially degradable and chemically labile organic compounds can have old ${ }^{14} \mathrm{C}$ ages, the concept of chemical recalcitrance has been challenged and more emphasis given to spatial separation of substrates and decomposers, stabilization of OC through association with minerals, and soil environmental constraints (Dungait et al., 2012; Fontaine et al., 2007; Marschner et al., 2008; Schmidt et al., 2011).

Density fractionation, which separates organic debris residing inside and outside aggregates (light fraction, LF) from OM bound to minerals (heavy fraction, HF), provides one method to study physical or physicochemical stabilization mechanisms (Golchin et al., 1994; Six et al., 1998; Sohi et al., 2001, 2005). Organic carbon in the LF basically consists of plant and animal residues at different stages of decomposition (Gregorich et al., 2006; Poirier et al., 2005; Wagai et al., 2009). A common concept assumes that LF-OC released from soil upon disruption of aggregates (occluded light fraction, oLF) has a smaller particle size, is chemically more degraded, and older than the physically unprotected free LF (fLF) (Golchin et al., 1994; Wagai et al., 2009). The review by Wagai et al. (2009) suggests that oLF-OC exhibits a large variation in age and chemical composition. This could be due to differences in soil type, vegetation, climate, or disturbance regime (Wagai et al., 2009), but the diversity of methods applied to separate the two fractions limits the comparability of studies (Cerli et al., 2012).

Organic matter of the HF comprises larger contributions of microbial residues than LF-OC (Golchin et al., 1994; KögelKnabner et al., 2008; Poirier et al., 2005). Compounds forming HF-OC can be direct decomposition products of LF-OC (Sanaullah et al., 2011), or dissolved OC (DOC) from the percolating soil solution (Kalbitz and Kaiser, 2008). Organic carbon storage in the HF is controlled by the availability and nature of binding sites at mineral surfaces. Iron $(\mathrm{Fe})$ and $\mathrm{Al}$ hydrous oxides rather than other clay-sized particles were shown to be good predictors for HF-OC, especially in acid forest soils (Kaiser et al., 2002; Kögel-Knabner et al., 2008; Mikutta et al., 2006).

Most evidence for the different stability of OC in density fractions comes from stable isotope $\left(\delta^{13} \mathrm{C}\right)$ and radiocarbon analyses, with the HF usually having the oldest OC (KögelKnabner et al., 2008; Trumbore, 1993, 2009). However, studies following the incorporation of "bomb" produced ${ }^{14} \mathrm{C}$, or determining the ${ }^{14} \mathrm{C}$ age of residues after oxidation or acid hydrolysis of the HF, demonstrate that the bulk HF-OC is itself a mixture of younger and older components (KögelKnabner et al., 2008; Swanston et al., 2005; Tan et al., 2007; Trumbore, 1993). This suggests that not the entire fraction is similarly stabilized. Also Swanston et al. (2002) and Crow et al. (2007) observed for forest topsoil layers that the decomposability of LF-OC was not necessarily different from that of HF-OC when incubating density fractions separately and normalizing mineralization rates to $\mathrm{OC}$ in the fractions.

Most studies on soil OC stability were restricted to topsoil layers, and our understanding of subsoil OC is still limited (Rumpel and Kögel-Knabner, 2011). Subsoils contain a large fraction of total OC stocks and are sensitive, for example, to land use changes (Don et al., 2009; Harrison et al., 2003; Rumpel and Kögel-Knabner, 2011). Therefore, consideration of entire soil profiles is required to understand the processes controlling OC storage and vulnerability to environmental changes.

The few studies of density fractions over the entire soil profile show declining contributions of LF-OC to total OC with soil depth (John et al., 2005; Kögel-Knabner et al., 2008). Jobbagy and Jackson (2000) stressed the importance of roots for OC depth profiles, but it is unknown if LF-OC and HF-OC profiles are similarly affected by rooting patterns. Also sorption of dissolved OC was assumed to be relevant for subsoil OC storage (Michalzik et al., 2003). Modelled estimates of the contribution of DOC to subsoil OC are however highly variable and mostly limited to forest soils (Kalbitz and Kaiser, 2008; Michalzik et al., 2003; Sanderman and Amundson, 2008).

Strongly increasing carbon ages, especially of HF-OC, with soil depth were assumed to be due to greater stability of HF-OC at depth (Kögel-Knabner et al., 2008) and can reflect differences in physicochemical protection between topsoil and subsoil layers. However, observed ${ }^{14} \mathrm{C}$-depth profiles may also be explained by downward mixing and sorption of aged dissolved OC (DOC) to subsoil layers as suggested by Kaiser and Kalbitz (2012). Alvarez and Alvarez (2000), Janzen et al. (1992), and Hassink (1995) observed that microbial biomass and in vitro mineralization rates were positively correlated to LF-OC at grassland and cropland sites when pooling topsoil and subsoil layers. No attempt was made to analyse topsoil and subsoil layers separately to see if, besides varying contributions of labile LF-OC, also stronger OC stability with depth affected decomposition rates.

We conducted a large-scale study of entire soil profiles to determine controls of depth profiles of OC in density fractions, and to see if general relations between soil OC stability and $\mathrm{OC}$ in density fractions exist for sites differing in soil type, vegetation, and land use. We aimed at studying:

1. general trends of OC, the OC-to-TN-ratio, $\delta^{13} \mathrm{C}$, and $\Delta{ }^{14} \mathrm{C}$ in density fractions with soil depth in undisturbed profiles;

2. the dependence of LF-OC depth profiles on root distribution and plant functional types; 
3. the relevance of dissolved OC transport for HF-OC formation in subsoils, and for shaping also ${ }^{14} \mathrm{C}$ depth profiles of the HF;

4. the dependence of bulk soil OC decomposability on fLF-OC as a potentially available energy source, and on OC stabilized in association with minerals irrespective of land-use, soil type, and soil depth;

Multiple replicates per site were analysed to quantify the importance of small-scale spatial variability for the OM fractions. Two independent measures were applied to determine OC stability: laboratory incubations, providing potential carbon $(\mathbf{C})$ mineralization rates, and ${ }^{14} \mathrm{C}$ analyses as an indicator of OC turnover under field conditions. Our data set vastly expands available information on the spatial and depth-dependent variation of OC in density fractions, ${ }^{14} \mathrm{C}$ in density fractions, and mineralization-based measures of soil OC turnover.

\section{Materials and methods}

\subsection{Soil sampling and sample treatment}

The twelve study sites were selected from the 52 main sites of the CarboEurope IP project (http://www.carboeurope.org/) to give geographical spread, equal numbers of different land use types, and to assure reliable long-term eddy covariance measurements. The latter was required since these sites are part of a long-term soil monitoring program (Schrumpf et al., 2011). Details on location, soil type, bulk densities, stone content, climate, land use, and total C stocks of the study sites are given in supplementary Table A1 and Schrumpf et al. (2011). The sites are all in level terrain to meet the requirements for eddy covariance.

Soil samples were collected in 2004. Deciduous forest sites (Hainich, Germany; Hesse, France; Sorø, Denmark), and coniferous forest sites (Norunda, Sweden; Le Bray, France; Wetzstein, Germany) were sampled from March to December, grassland sites (Laqueuille, France; Easter Bush, UK; Bugac, Hungary) from April to June; and arable soils (Carlow, Ireland; Grignon, France; Gebesee, Germany) in August and September, after harvest. Gebesee and Grignon sites were tilled before soil sampling but Carlow not. At all sites, except for Wetzstein and Norunda, 10 soil cores $(8.7 \mathrm{~cm}$ diameter, $60 \mathrm{~cm}$ length) were randomly selected out of 100 extracted soil cores per site (Schrumpf et al., 2011). Soil cores were divided into seven depth increments: 0-5, $5-10,10-20,20-30,30-40,40-50$, and $50-60 \mathrm{~cm}$. At the stone-rich sites Wetzstein and Norunda, samples from 10 soil monoliths ( $25 \mathrm{~cm}$ edge length) were selected. At Wetzstein, three mineral soil layers were sampled: $0-10,10-30$, and $30-$ $50 \mathrm{~cm}$. Soils at Norunda were collected to a depth of $10 \mathrm{~cm}$ in two segments $(0-5,5-10 \mathrm{~cm})$. A smaller auger $(3 \mathrm{~cm}$ diameter) was used to extend the sampling depth to $40 \mathrm{~cm}$ with three replicates per site. These subsoil samples could not be used for bulk density determinations, so C stocks were only calculated for the upper soil layers at Norunda. Organic surface layers were collected at the forest sites by horizon (Oi, Oe, Oa), using a metal frame of $25 \mathrm{~cm}$ side length prior to mineral soil sampling.

Coarse roots (diameter $>1 \mathrm{~mm}$ ) and gravel/stones ( $>4 \mathrm{~mm}$ ) were removed from field-moist samples in the laboratory before separating a subsample for mineralization experiments. After drying the remaining soil material at $40^{\circ} \mathrm{C}$, another subsample was taken for density fractionation, then the rest of the samples was sieved to $<2 \mathrm{~mm}$. Roots were dried at $70^{\circ} \mathrm{C}$ and their weight determined.

\subsection{Mineralization rates}

Field-moist bulk samples of organic layers and mineral soils to a depth of $30 \mathrm{~cm}$ (corresponding to 16 and $100 \mathrm{~g}$ dry weight, respectively) were placed in plastic containers $\left(50 \mathrm{~cm}^{2}\right.$ surface area, $466 \mathrm{~cm}^{3}$ volume) fitted with a lid with a $5 \mathrm{~mm}$ diameter aperture that allowed for gas exchange between the measurements. These soil microcosms were incubated at $15{ }^{\circ} \mathrm{C}$ for 20 days. We decided for short-time incubation because we were interested in comparing $\mathrm{CO}_{2}$-release rates in the fresh material (before substantial decomposition) as an indicator for the portion of labile OC. The soil moisture level was set to $60 \%$ of the water-holding capacity, either by addition of distilled water or by letting them dry up to the appropriate water content. The Oi layer of the site Sorø was not incubated.

To determine $\mathrm{C}$ mineralization in the soil sample, the container lid was periodically replaced with an airtight lid with a rubber septum. Background gas samples were taken after $15 \mathrm{~min}$ from the headspace with a syringe and injected into a gas chromatograph (HP 5890, Hewlett Packard Company, Avondale, PA, USA). Measurements were repeated when an appropriate amount of $\mathrm{CO}_{2}$ had accumulated in the closed container, which took between $2 \mathrm{~h}$ (humus) and about $5 \mathrm{~h}$ (mineral soil), depending on the respiration rate. $\mathrm{CO}_{2}$ measurements were performed once a week after the starting day.

The $\mathrm{CO}_{2}$ evolution was calculated as the difference between two $\mathrm{CO}_{2}$ concentrations. Accumulation of $\mathrm{CO}_{2}$ increases the dissolution of $\mathrm{CO}_{2}$ in the water phase of the sample. Since the dissolution is $\mathrm{pH}$-dependent (increases with $\mathrm{pH}$ ), the $\mathrm{pH}$ was considered in the calculations. The mass of $\mathrm{C}$ evolved per container and hour was calculated following Persson et al. (1989) and Persson and Wirén (1993):

$R_{C}=\frac{12 \times 10^{6}\left(C-C_{0}\right) p\left(\frac{V_{\mathrm{g}}}{R \times T}+A \times V_{\mathrm{aq}}\right)}{t}$,

where $R_{C}$ is the mineralization rate $\left(\mu \mathrm{g} \mathrm{CO}_{2}-\mathrm{C}\right.$ container $\left.^{-1}\right)$, $C$ is the sample concentration of $\mathrm{CO}_{2}\left(\mathrm{~mL} \mathrm{~mL}^{-1}\right), C_{0}$ is the $\mathrm{CO}_{2}$ concentration $\left(\mathrm{mL} \mathrm{mL}^{-1}\right)$ in the container directly after closure, $t$ is the time between closure and gas sampling 
(hours), $V_{\mathrm{g}}$ is the gas volume $(\mathrm{mL})$ in the container, $V_{\mathrm{aq}}$ is the water volume (L) in the container, $p$ is the atmospheric pressure (atm) when the container was closed, $R$ is the gas constant (82.05) $\left(\mathrm{mL} \mathrm{atm}^{\circ} \mathrm{K}^{-1} \mathrm{~mol}^{-1}\right), T$ is the temperature during incubation $\left(288.15^{\circ} \mathrm{K}\right)$, and $A$ is the $\mathrm{pH}$-dependent $\mathrm{CO}_{2}$ absorption factor, where

$A=K_{1}+\frac{K_{1} \times K_{2}}{\left[\mathrm{H}^{+}\right]}+\frac{K_{1} \times K_{2} \times K_{3}}{\left[\mathrm{H}^{+}\right]^{2}}$,

where $K_{1} \quad$ (Henry's law constant $)=4.79 \times 10^{-2}$ $\left(\mathrm{mol} \mathrm{L}^{-1} \mathrm{~atm}^{-1}\right), \quad K_{2}=3.81 \times 10^{-7} \quad\left(\mathrm{~mol} \mathrm{~L}^{-1}\right)$, $K_{3}=3.71 \times 10^{-11}\left(\mathrm{~mol} \mathrm{~L}^{-1}\right) \quad($ all values given for $\left.288.15^{\circ} \mathrm{K}\right)$ and $\left[\mathrm{H}^{+}\right]=10^{-\mathrm{pH}}\left(\mathrm{mol} \mathrm{L}^{-1}\right)$. The A factors were calculated from the final $\mathrm{pH}$ values at day 20 .

The mean $\mathrm{CO}_{2}$ evolution rate per day was based on cumulative estimates up to day 20. Mineralization rates were calculated as $\mathrm{g} \mathrm{CO}_{2}-\mathrm{C}$ (g dry weight $)^{-1} \mathrm{~d}^{-1}$ based on the respective dry soil masses in the container. Absolute mineralization rates depend not only on the decomposability of OC in the samples, but also on the total amount of OC present in the samples. Therefore we calculated the OC-normalized $\mathrm{CO}_{2}$-release $\left(\mathrm{g} \mathrm{CO}_{2}-\mathrm{C}\left(\mathrm{g} \mathrm{C}^{-1} \mathrm{~d}^{-1}\right)\right.$ by dividing the $\mathrm{CO}_{2}$ release per $\mathrm{g}$ soil by the $\mathrm{OC}$ concentration of the respective sample. We will refer to this value in the following as specific mineralization.

The $\mathrm{CO}_{2}$ evolution per $g$ soil was converted into $\mathrm{CO}_{2}$ evolution for each soil layer $i(\mathrm{Cmin})$ and full soil profiles (Cmin profile, Eqs. 3, 4 and 5).

$$
\begin{aligned}
\mathrm{FE}_{i}\left(\mathrm{~g} \mathrm{~m}^{-2}\right) & =\mathrm{BD}_{i}\left(\mathrm{~g} \mathrm{~cm}^{-3}\right) \times \text { layer thickness }_{i}(\mathrm{~cm}) \\
& \times \mathrm{FE} \text { content } \\
i & \times 10000
\end{aligned}
$$

$\mathrm{Cmin}_{i}\left(\mathrm{~g} \mathrm{CO}_{2}-\mathrm{C} \mathrm{m}^{-2} \mathrm{~d}^{-1}\right)$

$=\mathrm{CO}_{2}$-evolution $i\left(\mathrm{~g} \mathrm{CO}_{2}-\mathrm{Cg}^{-1} \mathrm{~d}^{-1}\right) \times \mathrm{FE}_{i}\left(\mathrm{~g} \mathrm{~m}^{-2}\right)$

Cmin profile $\left(\mathrm{g} \mathrm{CO}_{2}-\mathrm{C} \mathrm{m}^{-2} \mathrm{~d}^{-1}\right)$

$=\sum \mathrm{Cmin}_{i}\left(\mathrm{~g} \mathrm{CO}_{2}-\mathrm{C} \mathrm{m}^{-2} \mathrm{~d}^{-1}\right)$,

where $\mathrm{BD}_{i}$ is the bulk density, and $\mathrm{FE}$ content ${ }_{i}$ the fine earth content (portion of stone-free soil weight) for each soil core and layer as given in Schrumpf et al. (2011). For the forest litter layers, the dry-mass of litter per area was used to determine Cmin. The contribution of the litter layer to total $\mathrm{CO}_{2}$-evolution was calculated by dividing the $\mathrm{CO}_{2}$ evolved from sum of the litter horizons by the $\mathrm{CO}_{2}$ evolved from the total profile (including the litter layer).

Because roots and mycorrhizal mycelia were partly removed by sieving, and since there was a delay of 3 weeks between sampling and start of incubation, we considered the estimated $\mathrm{C}$ mineralization to be of heterotrophic and not autotrophic origin.

\subsection{Density fractionation}

Density fractionation was carried out for 720 samples, with two analytical replicates per sample. The fractionation was performed following ideas of Golchin et al. (1994) and Sohi et al. (2001), using sodium polytungstate (SPT, C and N poor, Tungsten Compounds, Grub am Forst, Germany) solution of $1.6 \mathrm{~g} \mathrm{~cm}^{-3}$ density (Cerli et al., 2012; Golchin et al., 1994).

Twenty-five g ( $25 \mathrm{~g})$ of soil were placed into $750 \mathrm{~mL}$ centrifugation bottles and $125 \mathrm{~mL}$ SPT solution was added. Bottles were gently shaken by hand to release the free light fraction (fLF-OM). Suspensions were allowed to settle for one hour, and then centrifuged at $5500 \mathrm{~g}$ for $30 \mathrm{~min}$. The floating fLF was decanted onto glass fibre filters (GF 6, Whatman $\mathrm{GmbH}$, Dassel, Germany) and filtered under vacuum. The SPT solution was placed back into the centrifugation bottles after adjustment of density. The occluded LF (oLF) was obtained by treating the samples with ultrasound. Tests were performed for each site to determine the sonication energy required for complete aggregate disruption by observing the effects of stepwise increase of sonication energy (Cerli et al., 2012; Schmidt et al., 1999; Wander, 2004). Complete disruption of aggregates was assumed when no further occluded OC was released at the next sonication step and no aggregates were visible any more. OC concentrations of the oLF, visible plant debris still adhering to mineral particles in the $\mathrm{HF}$, and scanning electron imaging were used as indicators for the full separation of oLF and HF-OC (results not shown). Calorimetrical calibration of the sonicator (Bandelin $\mathrm{GmbH}$, Berlin, Germany) according to Schmidt et al. (1999) was performed to provide an estimate for the energy applied. Energy input of $100 \mathrm{~J} \mathrm{~mL}^{-1}$ was sufficient for sandy soils (Bugac, Bordeaux), and between 300 and $450 \mathrm{~J} \mathrm{~mL}^{-1}$ for most other soils. For the clay-rich Hainich soil, the energy input had to be raised to up to $900 \mathrm{~J} \mathrm{~mL}^{-1}$. The respective energy required was then applied as one dose to each of the samples. After sonication, samples were allowed to stand for one hour, and then centrifuged at $5500 \mathrm{~g}$ for $30 \mathrm{~min}$. The floating oLF was collected on a glass fibre filter as described above. The fLF and oLF fractions were washed with deionized water to remove SPT until the conductivity of the rinsing solution was $<50 \mu \mathrm{S}$. The settled heavy fraction (HF) was washed with deionised water to remove SPT until electrical conductivity was $<200 \mu \mathrm{S}$ for soils containing carbonates (steady dissolution of carbonates maintained the electrical conductivity at that level) and $<50 \mu \mathrm{S}$ for all other soils. The SPT collected from the filtration of the light fractions (fLF, oLF) was cleaned and recycled as described by Six et al. (1999) to avoid transfer of $\mathrm{C}$ and $\mathrm{N}$ between samples. Light fractions were dried at $40^{\circ} \mathrm{C}$ and subsequently ground in an agate mortar. The HF were freeze dried, sieved to $<2 \mathrm{~mm}$ and ground with a ball mill. Fractionation of samples from the andic soils at Laqueuille was performed on field-moist samples to avoid the occlusion of fLF material within aggregates forming during drying. The density of the applied SPT solution 
was adapted to the samples' water content to achieve a final solution density of $1.6 \mathrm{~g} \mathrm{~cm}^{-3}$.

\subsection{Analyses of soil samples and density fractions}

Total $\mathrm{C}$ and $\mathrm{N}$ in $<2 \mathrm{~mm}$ soil separates and density fractions were determined by dry combustion (VarioMax $\mathrm{CH}$ analyser for bulk samples and heavy fractions; Vario EL for light fractions; both Elementar Analysensysteme GmbH, Hanau, Germany). At the sites Hainich, Gebesee and Carlow, the carbonate $\mathrm{C}$ of bulk samples was determined after dry combustion of the samples in a muffle furnace at $450^{\circ} \mathrm{C}$ for $16 \mathrm{~h}$ (Steinbeiss et al., 2008). Carbonate $\mathrm{C}$ of bulk soil samples of the sites Bugac and Sorø, of heavy fractions of the sites Hainich, Gebesee, Carlow, Bugac and Sor $\varnothing$ was analysed by determining the evolution of $\mathrm{CO}_{2}$ upon treatment with phosphoric acid (C-MAT 550, Ströhlein GmbH, Viersen, Germany). Concentrations of OC were calculated as the difference between total and inorganic C. Stocks of OC and TN in density fractions were calculated based on the fine earth mass per area for each sample (Schrumpf et al., 2011). For $\delta^{13} \mathrm{C}$ analyses, ground samples were weighted into tin capsules, and combusted in an oxygen stream using an elemental analyser (NA 1110, CE Instruments, Milan, Italy). Samples having carbonates were treated with sulphurous acid inside the capsules, and dried at $60^{\circ} \mathrm{C}$ before combustion. Evolved $\mathrm{CO}_{2}$ was analysed using an isotope ratio mass spectrometer (IRMS; Delta C or DELTA+XL, Thermo Finnigan MAT, Bremen, Germany). Isotope ratios are given as $\delta^{13} \mathrm{C}$ in per mille $(\% o$ ) relative to the international reference standard $\mathrm{v}$ PDB using NBS19 (Werner and Brand, 2001).

Three replicates of three soil depths $(0-5,10-20,30-$ $40 \mathrm{~cm}$ ) were analysed for ${ }^{14} \mathrm{C}$ of all sites except for Le Bray, because samples from this site were lost during postal transfer. The low ${ }^{14} \mathrm{C}$ values of the $\mathrm{LF}$ at Easter Bush, Carlow, and Grignon indicate that the samples contain fossil C (see results section). Radiocarbon data of these sites can therefore not be used as an indicator for the turnover of OC derived from recent vegetation. Additional radiocarbon analyses of two more replicate cores and of bulk soil samples were therefore only performed for of the other sites. Sample preparation and analyses were performed at the ${ }^{14} \mathrm{C}$ laboratory at Jena, Germany (Steinhof et al., 2004). Samples were weighed into tin capsules and combusted in an elemental analyser. Samples containing carbonate were decalcified prior to combustion (as for $\delta^{13} \mathrm{C}$ analyses described above). The evolved $\mathrm{CO}_{2}$ was transferred into a glass tube cooled by liquid nitrogen and containing an iron catalyst. Reduction of $\mathrm{CO}_{2}$ to graphite was carried out at $600{ }^{\circ} \mathrm{C}$ under hydrogen gas atmosphere. The graphite was analysed by ${ }^{14} \mathrm{C}$ AMS (3MV Tandetron 4130 AMS ${ }^{14} \mathrm{C}$ system: High Voltage Engineering Europe, HVEE, the Netherlands). ${ }^{14} \mathrm{C}$ is given in per mille $(\%) \Delta \Delta^{14} \mathrm{C}$, which is the relative difference in activity with respect to a standard (oxalic acid standard NBS SRM 4990C), after normalization to $\delta^{13} \mathrm{C}$ (fractionation cor- rection) and correction for decay between 1950 and analyses in 2009 and 2010.

Soil $\mathrm{pH}$ was measured in the supernatant after shaking a soil-distilled water suspension ( $1: 1$ by volume) for $2 \mathrm{~h}$, followed by sedimentation for $22 \mathrm{~h}$. Oxalate-extractable iron and aluminium $\left(\mathrm{Fe}_{\mathrm{o}}, \mathrm{Al}_{\mathrm{o}}\right)$ were determined using $0.2 \mathrm{M}$ oxalate solution (pH 3) (Schwertmann, 1964). Dithioniteextractable iron and aluminium $\left(\mathrm{Fe}_{\mathrm{d}}, \mathrm{Al}_{\mathrm{d}}\right)$ were analysed by the cold dithionite-citrate method (Holmgren, 1967). Aluminium and iron in extracts were measured by InductivelyCoupled Plasma Atomic Emission Spectroscopy (ICP-AES, Optima 3300 DV, Perkin-Elmer, Norwalk, CT, USA). Particle size distribution was carried out following Schlichting and Blume (1964), with fractions $<63 \mu \mathrm{m}$ being analysed using a Sedigraph 5100 (Micromeritics Corp., Nocross, USA).

The average dry mass of roots sorted out during sample preparation from each depth segment of the 100 soil cores was used as an indicator for root distributions. In order to achieve a relative measure for how much each of the soil layers contributed to the total root mass in total cores, root masses of each $10 \mathrm{~cm}$ depth segment were divided by the total root mass of the cores. The same was done for OC stocks of each of the density fractions.

\subsection{Statistical analyses}

Results are presented as means \pm standard error unless indicated otherwise. Analyses of variance (ANOVA) were used to test for significant differences between land use types $(p<0.05)$. Scheffé tests were used for post-hoc analysis. To determine relations between variables, Pearson correlation coefficients were calculated and tested for significance with a two-tailed $t$ test ( $p<0.05$, or $p<0.01$, as given in figures). Statistical analyses were performed using the software package SPSS 16.0 for Windows.

\section{Results}

\subsection{Density fractions}

\subsubsection{General trends for organic carbon, total nitrogen, and carbon isotopes in density fractions of soil profiles}

Mass losses and OC recoveries during density fractionation for each site are given in Supplement Table A2. General trends in depth distributions of OC contents, OC-toTN-ratios, $\delta^{13} \mathrm{C}$, and $\Delta^{14} \mathrm{C}$ values for undisturbed soil profiles are presented in Fig. 1. The distribution of OC over LF and HF showed a large variation between sites. Total OC stocks in $0-60 \mathrm{~cm}$ ranged from 0.4 to $11.2 \mathrm{~kg} \mathrm{~m}^{-2}$ for the $\mathrm{LF}$ and from 5.6 to $22.0 \mathrm{~kg} \mathrm{~m}^{-2}$ for the HF. (Fig. 2a, Supplement Table A3). In accordance with total OC, stocks of LF-OC and HF-OC were the largest in the uppermost layers and declined with depth at all sites. The decline with depth 


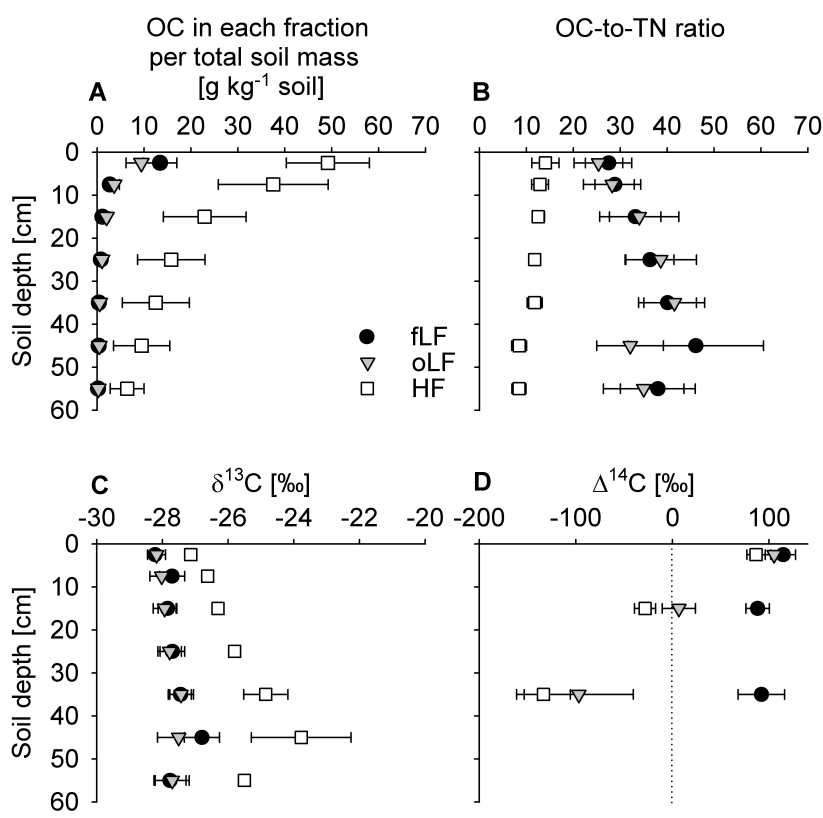

Fig. 1. Depth profiles of average (A) masses of OC in the fLF (free light fraction), oLF (occluded light fraction) and HF (heavy fraction) per $\mathrm{kg}$ soil, (B) OC-to-TN-ratios of fractions, (C) $\delta^{13} \mathrm{C}$ of OC in fractions, and (D) $\Delta^{14} \mathrm{C}$ values of $\mathrm{OC}$ in fractions of unploughed sites (Hainich, Hesse, Sorø, Bugac, Laqueuille, Norunda). As C4 grasses occurred at the grassland site Bugac it was excluded from the average of $\delta^{13} \mathrm{C}$ values. Error bars are standard errors $(n=6$ except for $\delta^{13} \mathrm{C} n=5$ ). Wetzstein was not included because of different depth increments analysed (see Supplement Fig. A1).

was more pronounced for LF-OC than for HF-OC (Fig. 1). Accordingly, significantly larger proportions of total LF-OC $(43 \pm 5 \%)$ than of HF-OC $(29 \pm 2 \%)$ stocks were in the upper $10 \mathrm{~cm}$ of the mineral soil. On average across sites, the contribution of LF to total OC decreased from $30 \pm 16 \%$ (S.D.) in the $0-5 \mathrm{~cm}$ layer to $14 \pm 12 \%$ in the $50-60 \mathrm{~cm}$ layer.

The OC-to-TN ratios differed significantly $(p<0.05)$ between fractions in the $0-5 \mathrm{~cm}$ layer and decreased in the order fLF $(28 \pm 3)>\operatorname{oLF}(24 \pm 3)>\operatorname{HF}(14 \pm 2)$ across sites. The HF contributed on average $8 \pm 1 \%$ more to TN stocks than to OC stocks in that layer. The OC-to-TN ratios of HF decreased with soil depth for most sites while OC-to-TN ratios of LF increased (Fig. 1). TN contents close to the detection limit in some subsoils probably contributed to greater variability of OC-to-TN ratios at depth.

In general, $\mathrm{HF}-\mathrm{OC}$ had significantly less negative $\delta^{13} \mathrm{C}$ values than fLF and oLF at all soil depths, while no general trend for differences between $\delta^{13} \mathrm{C}$ values of $\mathrm{FLF}$ and oLF was found (Fig. 1). The $\delta^{13} \mathrm{C}$ of all fractions increased with depth. The comparatively heavy $\delta^{13} \mathrm{C}$ values of fLF and oLF of the semiarid grassland site Bugac (Fig. A1) are due to the presence of $\mathrm{C} 4$ grasses, which were not observed at the other sites.
Most fractions from the $0-5 \mathrm{~cm}$ layer had positive $\Delta^{14} \mathrm{C}$ values, reflecting influence of bomb-produced radiocarbon, and $\Delta^{14} \mathrm{C}$ decreased in the order fLF $>\mathrm{oLF}>\mathrm{HF}$ (Fig. 1). Only the fLF and HF were significantly different $(p<0.05)$ in the $0-5 \mathrm{~cm}$ layer. Correlations between $\Delta^{14} \mathrm{C}$ of fLF and of oLF as well as between $\Delta^{14} \mathrm{C}$ of oLF and $\mathrm{HF}$ at $0-5 \mathrm{~cm}$ at undisturbed sites point at a link between turnover times of fractions in the uppermost but not in deeper soil layers (Fig. 3).

The $\Delta^{14} \mathrm{C}$ of the fLF showed no consistent trend with depth across sites and was usually above zero, while the $\Delta{ }^{14} \mathrm{C}$ of oLF decreased with depth (Fig. 1). Except for the croplands, where the soil profiles were disturbed by ploughing, also the $\Delta^{14} \mathrm{C}$ of HF decreased linearly with soil depth (Fig. 1). Accordingly, differences between fractions became more pronounced at deeper soil layers.

The three sites Easter Bush, Carlow, and Grignon had very low $\Delta^{14} \mathrm{C}$ values of the $\mathrm{LF}$ compared to other sites (Fig. 4). The oldest modelled average age of an LF-sample measured was $11150-11300 \mathrm{yr}$ (97.7\% probability, OxCal version 4.1.7; Ramsey, 1995) at Carlow, 18 950-19650 yr at Easter Bush, and 38 500-40 $500 \mathrm{yr}$ at Grignon. These values suggest that fossil $\mathrm{C}$ contributed to the LF at these sites. This assumption is supported by wide OC-to-TN ratios in the LF (Fig. 3). Accordingly, radiocarbon data from these sites cannot be used as an indicator for the turnover of OC derived from recent vegetation. Therefore, these sites had to be excluded from some of the analyses as indicated in the figures.

\subsubsection{Impact of land use and vegetation type}

The amount of OC stored in density fractions and their depth distribution differed between land use types. Croplands had smallest average LF-OC stocks in full soil profiles $\left(0.85 \pm 0.41 \mathrm{~kg} \mathrm{OC} \mathrm{m}^{-2}\right.$ in $0-60 \mathrm{~cm}$, excluding Grignon because large amounts of fossil OC contributed to LF-OC in subsoils) of all studied land use types (Fig. 2a). Homogenization of topsoil layers $(0-30 \mathrm{~cm})$ by ploughing was evident in the depth profiles of OC concentrations and stocks, OC-to-TN ratios, $\delta^{13} \mathrm{C}$, and $\Delta^{14} \mathrm{C}$ of density fractions of the cropland sites (Fig. S1). Former ploughing affected the OC depth distribution of the grassland site at Easter Bush and the conifer forest at Le Bray (Fig. S1).

Average LF-OC-stocks in full soil profiles of the deciduous forest and the grassland sites were quite similar $\left(1.91 \pm 0.36\right.$ and $1.92 \pm 0.04 \mathrm{~kg} \mathrm{OC} \mathrm{m}^{-2}$, respectively). Nevertheless, grassland and deciduous forest sites showed different patterns in the depth distribution of LF-OC (Fig. 5). The upper $10 \mathrm{~cm}$ of the soil profile contributed significantly more to total LF-OC stocks at the grassland sites $(71 \pm 5 \%$, excluding the ploughed site Easter Bush) than at the deciduous forest $(41 \pm 3 \%)$ and the cropland sites $(35 \pm 3 \%$, excluding Grignon). Similarly, roots in the $0-10 \mathrm{~cm}$ layer of grasslands contributed more to total root masses within entire soil profiles than at deciduous forest sites $(78 \pm 3 \%$ at grasslands; 

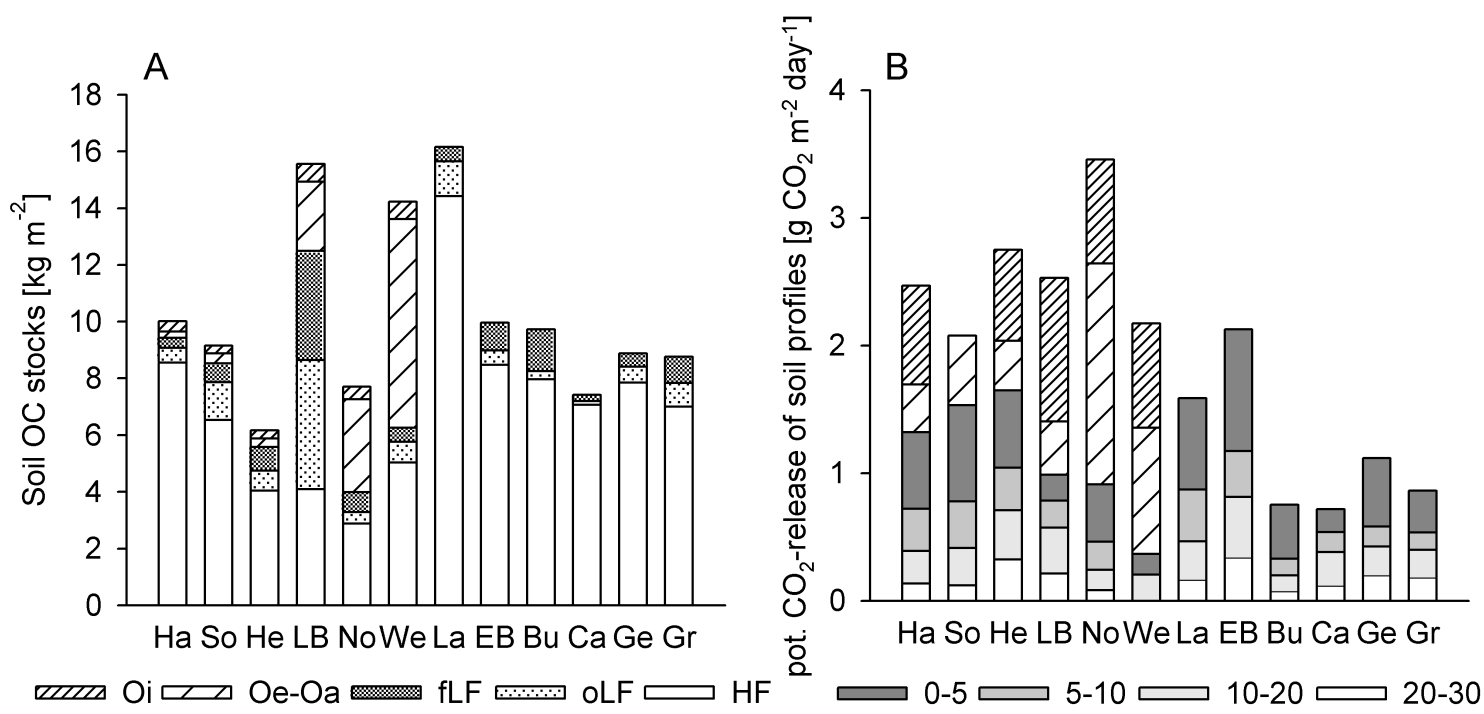

Fig. 2. The left graph (A) presents soil OC stocks of the litter layer (Oi, Oe-Oa) and in density fractions (fLF: free light fraction, oLF: occluded light fraction, HF: heavy fraction) of the mineral soil $(0-30 \mathrm{~cm})$; the right graph $(\mathbf{B})$ potential $\mathrm{CO}_{2}$-release per unit area at a temperature of $15^{\circ} \mathrm{C}$ and optimal soil moisture for each studied soil layer (Ha: Hainich, So: Sor $\varnothing$, He: Hesse, LB: Le Bray, No: Norunda, We: Wetzstein, La: Laqueuille, EB: Easter Bush, Bu: Bugac, Ca: Carlow, Ge: Gebesee, Gr: Grignon, Wetzstein: first bar below Oe-Oa is 0-10 cm, second bar 10-30 cm; Sorø: Oi layer was not incubated).
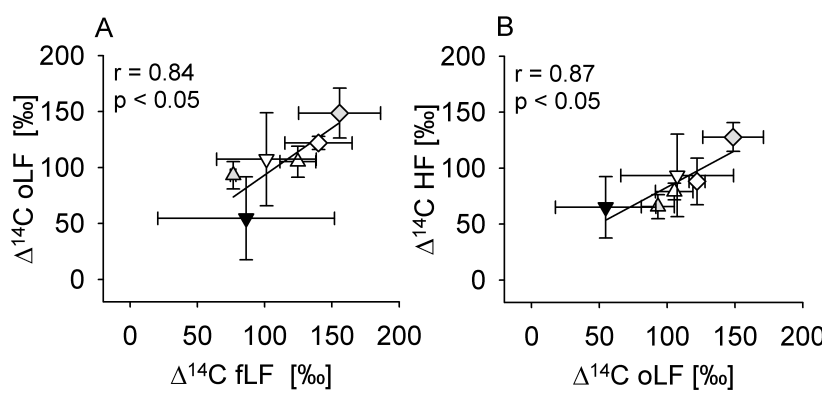

Fig. 3. Relation between the $\Delta^{14} \mathrm{C}$ of fLF (free light fraction) and oLF (occluded light fraction) (left, $\mathbf{A}$ ), and between the OC of the $\mathrm{oLF}$ and $\mathrm{HF}$ (heavy fraction, B) at $0-5 \mathrm{~cm}$ soil depth. Only undisturbed sites having no fossil $\mathrm{C}$ are shown (Hainich, Hesse, Sorø, Bugac, Laqueuille, Norunda; black: coniferous forest, dark grey: croplands, light gray: grasslands, white: deciduous forests).

$43 \pm 4 \%$ at deciduous forests) (Fig. 5). The portion of total fLF-OC $(0-60 \mathrm{~cm})$ located in $0-10 \mathrm{~cm}$ was positively correlated to the portions of total root masses located in $0-10 \mathrm{~cm}$ across undisturbed sites $(r=0.96, p<0.01)$, suggesting that root litter is an important source for LF-OC shaping its depth profile. There also seemed to be a positive correlation between root mass and fLF-OC in the $0-10 \mathrm{~cm}$ layer, but for the coniferous forest sites and the sandy site Bugac, amounts of fLF-OC per $g$ roots were larger than for the remaining sites (Fig. 6).

The correlation between root masses and OC in the HF in $0-10 \mathrm{~cm}$ was significant for all sites (Fig. 6). Furthermore, HF-OC declined less strongly with depth than LF-OC at the grassland sites (Fig. 5). This indicates that besides root litter input also other factors shape the depth profiles of HF-OC.

\subsubsection{Soil properties influencing density fractions}

The fraction of OC present as LF in the $0-10 \mathrm{~cm}$ layer depended on soil texture and $\mathrm{pH}$ (Fig. 7). The contribution of the LF to total OC declined with increasing clay content, while the proportion of HF-OC increased accordingly. The coniferous forests with low $\mathrm{pH}$ had larger proportions of OC in the LF than the other sites.

Absolute HF-OC concentrations across sites in the 0 $10 \mathrm{~cm}$ layer did not depend on the clay content but were positively correlated to oxalate-extractable $\mathrm{Fe}$ and $\mathrm{Al}$ (Fig. 8). Also, stocks of HF-OC to $30 \mathrm{~cm}$ depth related positively to stocks of oxalate-extractable $\mathrm{Al}(r=0.85, p<0.01)$ and $\mathrm{Fe}$ $(r=0.75, p<0.01)$ at the same depth (data not shown). Relations between texture or pedogenic oxides and OC in density fractions were less clear in subsoils, and either not significant or dependent on one sampling site only (i.e., the Andosol at Laqueuille for pedogenic oxides).

\subsection{Mineralization rates}

Evolution of $\mathrm{CO}_{2}$ per $\mathrm{g}$ soil showed large variation among sites and decreased with soil depth from a mean $( \pm$ S.E. for all sites) of $13.7 \pm 8.4 \mu \mathrm{g} \mathrm{CO} 2-\mathrm{C}(\mathrm{g} \mathrm{dwt})^{-1} \mathrm{day}^{-1}$ in the $0-5 \mathrm{~cm}$ layer to $1.5 \pm 0.7 \mu \mathrm{g} \mathrm{CO}_{2}-\mathrm{C}(\mathrm{g} \mathrm{dwt})^{-1} \mathrm{day}^{-1}$ in the $20-30 \mathrm{~cm}$ layer (Fig. 9, Supplement Fig. A2). With the organic layers included, and summing over all depths, incubation-based potential total soil mineralization rates 


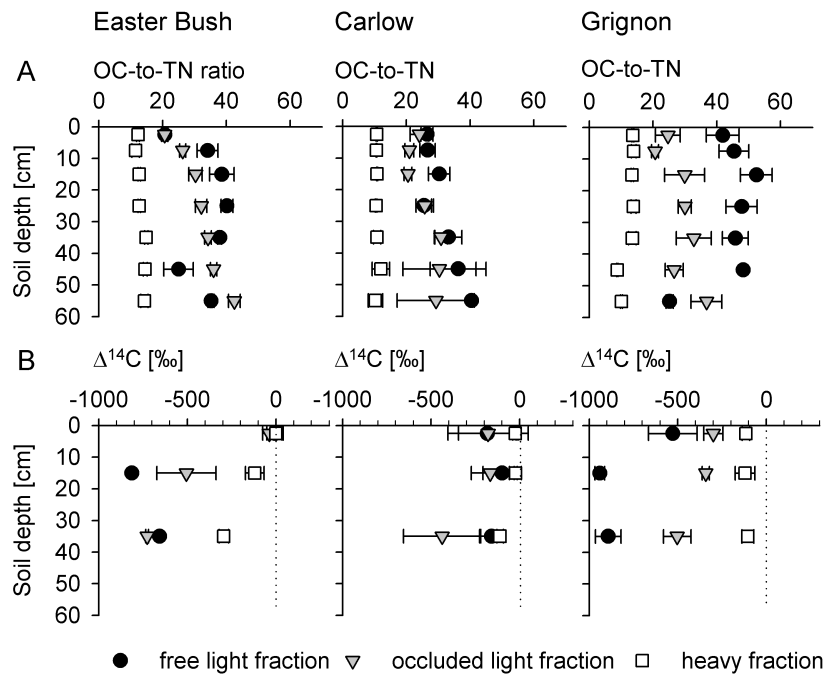

Fig. 4. Depth profiles of average OC-to-TN-ratios (A), and the $\Delta^{14} \mathrm{C}$ values of $\mathrm{OC}(\mathbf{B})$ in density fractions of the grassland site Easter Bush and the cropland sites Carlow and Grignon, all with low $\Delta^{14} \mathrm{C}$ values in the light fraction.

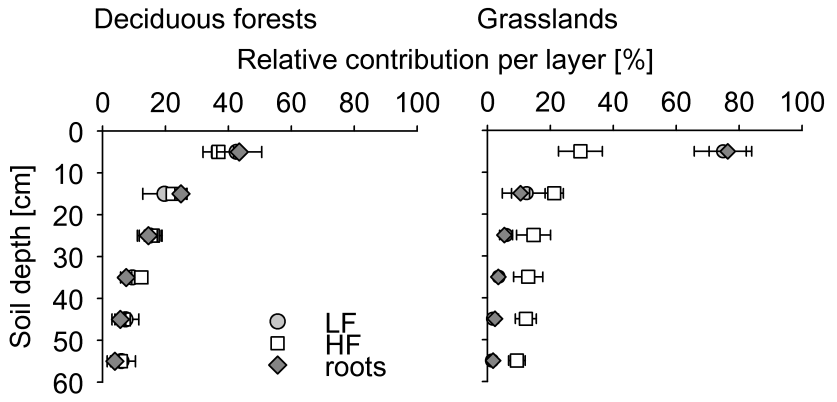

Fig. 5. Relative contributions of $10 \mathrm{~cm}$ depth increments to total stocks in $0-60 \mathrm{~cm}(100 \%)$ of OC with LF (light fraction) and HF (heavy fraction) and roots sorted out during sample preparation. Averages for deciduous forest and undisturbed grassland sites are shown.

were, on average, $2.75 \pm 0.36,2.33 \pm 0.12,1.49 \pm 0.40$, and $0.90 \pm 0.12 \mathrm{~g} \mathrm{CO}_{2}-\mathrm{C} \mathrm{m}^{-2}$ day $^{-1}$ for the coniferous, deciduous, grassland, and cropland sites, respectively (Fig. 3b). The organic layers contributed on average $71 \pm 5 \%$ and $39 \pm 8 \%$ to the potential total $\mathrm{CO}_{2}$ evolved in incubations of the coniferous and deciduous forest sites.

Mineralization rates for all sites and soil depths were positively correlated to OC concentrations of the incubated soil samples (correlations not shown).

Similar to mineralization rates $\left(\mathrm{CO}_{2}\right.$-release per $\mathrm{g}$ soil $)$, specific mineralization rates $\left(\mathrm{CO}_{2}\right.$-release per $\mathrm{g} \mathrm{OC}$ in the samples) also declined consistently with soil depth (except for the grassland site Bugac), indicating reduced OC turnover at depth (Fig. 9, Supplement Fig. A2).

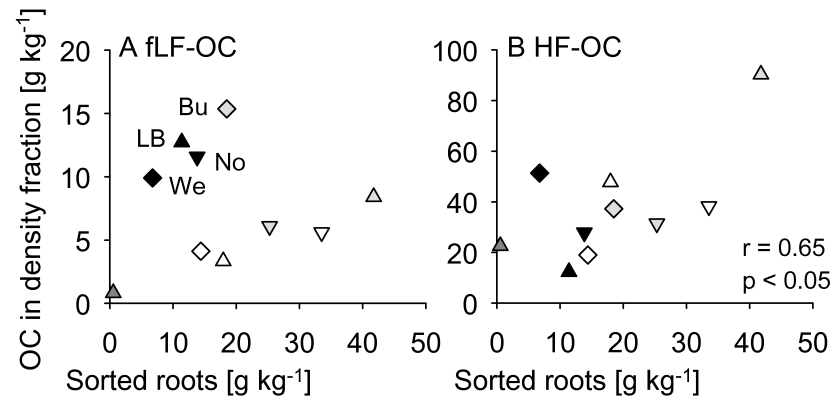

Fig. 6. Correlations between the amounts of sorted out roots in 0$10 \mathrm{~cm}$ with OC in the fLF (free light fraction, A) and OC in the HF (heavy fraction, B) for the study sites. Cropland sites Gebesee and Grignon were ploughed before sampling and therefore excluded (Bu: Bugac, LB: Le Bray, We: Wetzstein, No: Norunda, black: coniferous forest, dark grey: croplands, light gray: grasslands, white: deciduous forests).

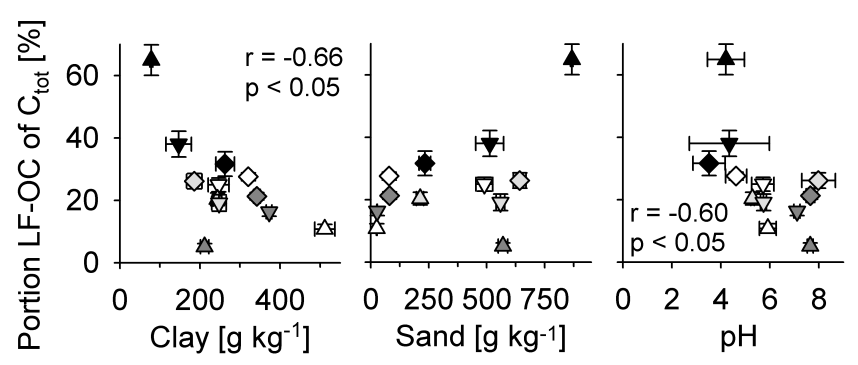

Fig. 7. Relation of the contribution of the LF (light fraction) at 0 $10 \mathrm{~cm}$ soil depth to total $\mathrm{OC}$ to clay content, sand content, and $\mathrm{pH}$ at 0-10 cm soil depth (black: coniferous forest, dark grey: croplands, light gray: grasslands, white: deciduous forests, $\mathrm{C}_{\text {tot }}$ : total OC).

\subsection{Links between OC stability and density fractions}

Organic carbon stability was assumed to be large in samples with small specific mineralization rates and when radiocarbon values indicate long average OC turnover times. Mineralization rates were positively related to $\mathrm{OC}$ of all three density fractions in the uppermost soil layer $(0-5 \mathrm{~cm}) . \mathrm{CO}_{2}-$ release per g OC in the fraction was greater for the LF than for the HF, suggesting that LF-OC contributed more to mineralization rates per $\mathrm{g}$ OC in the LF than HF-OC, which was more stable (Fig. 10). The sandy soils of the sites Bugac and Le Bray had mineralization rates lower than expected from the proportion of OC in the fLF and from total OC, indicating reduced decomposability of fLF-OC at these sites (Figs. 10 and 11). No significant relation between mineralization rates and OC in density fractions was observed in deeper soil layers across sites.

In order to determine the relation between density fractions and specific mineralization rates, we excluded the sites Grignon (large contribution of old OC not linked to current vegetation to LF) and Le Bray (high in subsoil LF due to deep ploughing before forest planting) from statistical analyses 


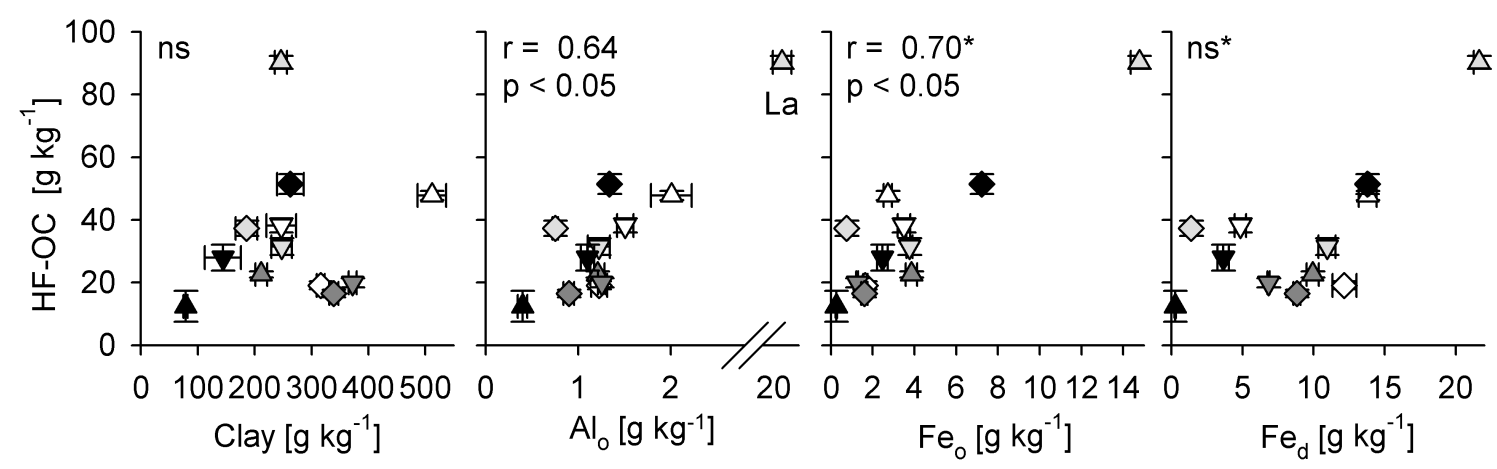

Fig. 8. Relation of the HF (heavy fraction)-OC per gram soil at $0-10 \mathrm{~cm}$ soil depth to concentrations of clay, oxalate-extractable $\mathrm{Al}\left(\mathrm{Al} \mathrm{O}_{\mathrm{O}}\right.$ ) and $\mathrm{Fe}\left(\mathrm{Fe}_{\mathrm{o}}\right)$, and dithionite-extractable $\mathrm{Fe}\left(\mathrm{Fe}_{\mathrm{d}}\right)$. Note, the $\mathrm{x}$-axis break before the data point of the site Laqueuille (Andosol, $\left.\mathrm{La}\right)$ for $\mathrm{Al} \mathrm{l}_{\mathrm{O}}$. This site was excluded from the correlation analyses. $\left(^{*}\right.$ : correlation was performed with log-transformed data, ns: not significant, black: coniferous forest, dark grey: croplands, light gray: grasslands, white: deciduous forests).

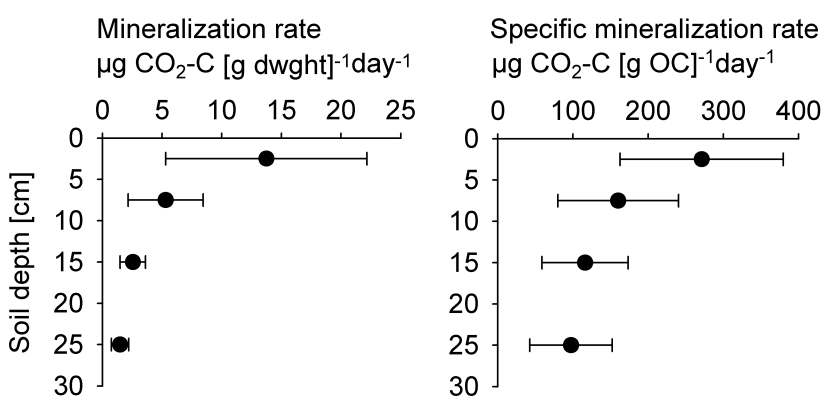

Fig. 9. Average $\mathrm{C}$ mineralization in the mineral soil over 20 days across all sites, given per g soil dry weight and per g OC $( \pm$ standard deviation).

but still present them in Fig. 11. No significant relation between OC with density fractions and specific mineralization rates was found for the uppermost soil layer (Fig. 11). In deeper soil layers however, specific mineralization rates were positively correlated with the portion of OC in the fLF, and negatively with the portion of OC in the HF. Here, specific mineralization rates were also significantly positively related to the absolute amount of fLF-OC and the OC-to-TN ratio of the fLF. No trend was observed for changes in the slopes of the regression between portions of OC in the fLF or the HF and specific mineralization rates with soil depth. Radiocarbon contents of bulk soil samples were not significantly related with specific mineralization rates or OC in density factions across sites in the uppermost soil layer. At $10-20 \mathrm{~cm}$ depth however, negative relations between specific mineralization rates and $\Delta^{14} \mathrm{C}$ values indicate faster turnover of more recent OC (Fig. 12). Radiocarbon contents of bulk samples confirm the positive correlation between average OC turnover and OC in fLF-OC, and the negative correlation with the portion of OC in the HF observed for specific mineralization rates in $10-20 \mathrm{~cm}$ (Fig. 11).

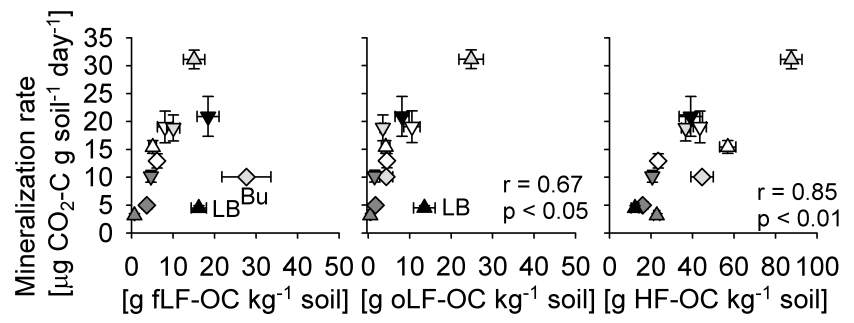

Fig. 10. Soil respiration per gram soil in relation to $\mathrm{fLF}-\mathrm{OC}$, oLFOC and HF-OC per dry weight soil at $0-5 \mathrm{~cm}$ depth (LB: Le Bray, $\mathrm{Bu}$ : Bugac, fLF free light fraction, oLF occluded light fraction, HF heavy fraction, black: coniferous forest, dark grey: croplands, light gray: grasslands, white: deciduous forests).

\section{Discussion}

\subsection{General trends for $\mathrm{OC}$ in density fractions of soil profiles}

The results of our large-scale study support previous work showing that density fractionation separates total soil OC into fractions of different OC-to-TN ratios, $\delta^{13} \mathrm{C}$ values, and $\Delta^{14} \mathrm{C}$ values (Alvarez and Alvarez, 2000; Golchin et al., 1994; Janzen et al., 1992; Swanston et al., 2005). Poirier et al. (2005) showed that HF-OC was in a more advanced decomposition stage than LF-OC, and that more microbialderived OC contributed to HF-OC. This is in line with smaller OC-to-TN-ratios and larger $\delta^{13} \mathrm{C}$ values of the $\mathrm{HF}$ than the LF across study sites (Figs. 1 and 13). Declining OC-to-TN ratios and increasing $\delta^{13} \mathrm{C}$ values of the $\mathrm{HF}$ with soil depth agree with observations of bulk soils and were ascribed to more processed organic matter and larger contributions of microbial products to organic matter in subsoils (Boström et al., 2007; Ehleringer et al., 2000; Melillo et al., 1989). However, inorganic $\mathrm{N}$ could also contribute to smaller OC-to-TN-ratios in deeper soil layers with smaller organic matter contents (Nieder et al., 2011). Rising contributions of 

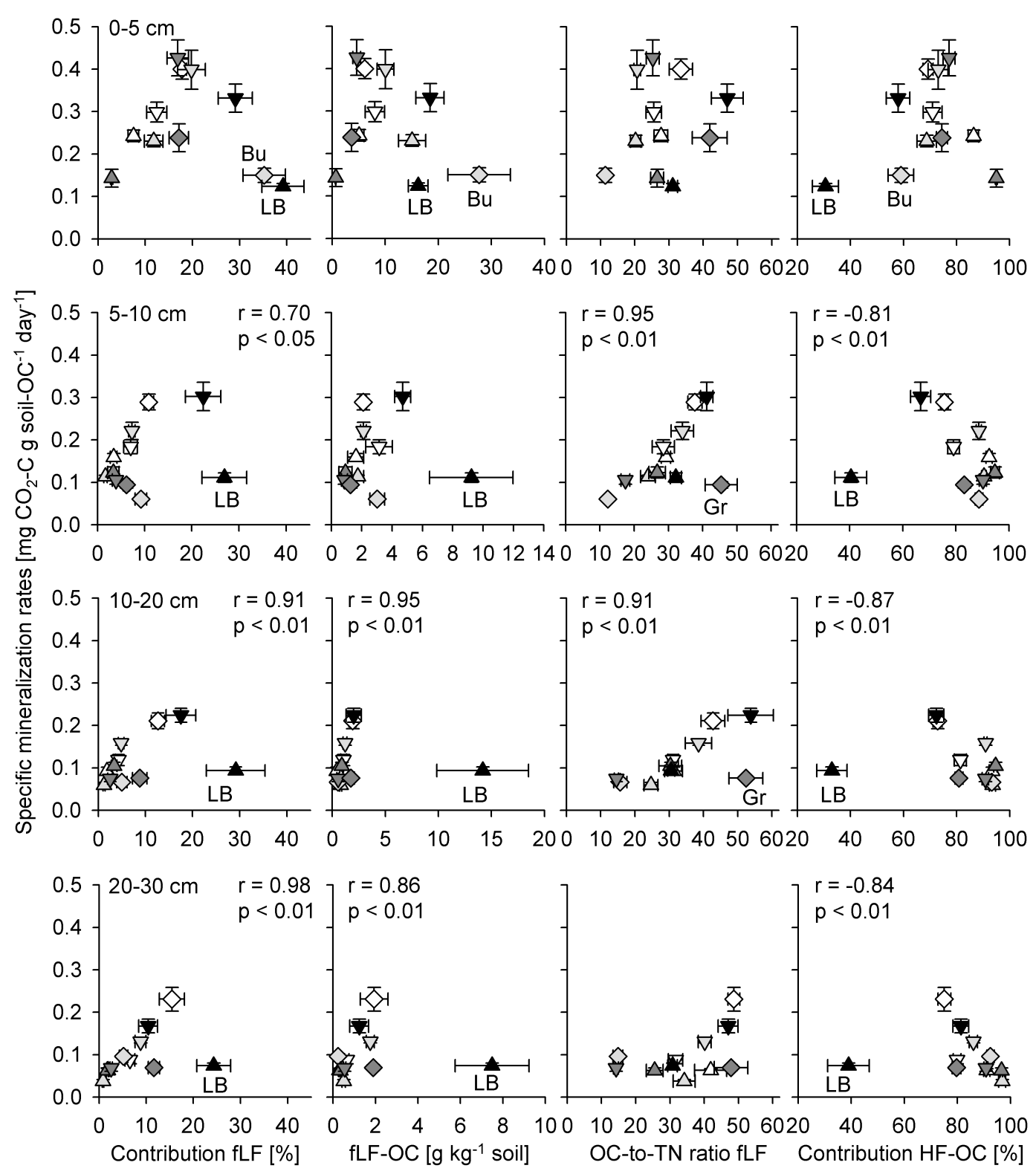

Fig. 11. Specific mineralization rates in relation to the proportion of free light fraction OC (fLF-OC), heavy fraction OC (HF-OC), the amount of fLF-OC per gram soil and the OC-to-TN ratio of the fLF for soil depths 0-5 cm, 5-10 cm, 10-20 cm, 20-30 cm. The sites Le Bray (black filled triangle up, LB) and Grignon (dark grey diamond, Gr) were excluded from correlation analyses (see text for details) (black: coniferous forest, dark grey: croplands, light gray: grasslands, white: deciduous forests).

${ }^{13} \mathrm{C}$-depleted $\mathrm{CO}_{2}$ from fossil fuel combustion in the atmosphere during the last century (so-called Suess effect) probably contribute to overall smaller $\delta^{13} \mathrm{C}$ values of all fractions in the upper soil layers (Boström et al., 2007; Ehleringer et al., 2000). Increasing OC-to-TN ratios of LF-OC can be due to smaller $\mathrm{N}$-contents of fine roots in deeper soil layers (Genenger et al., 2003; Göransson et al., 2007; Ugawa et al., 2010). Slightly smaller $\Delta^{14} \mathrm{C}$ values suggest longer mean residence times of fLF-OC in subsoils so that larger OC-to-TN ratios at depth can also be due to less decom- posed organic matter. Declining $\Delta^{14} \mathrm{C}$ values of fLF-OC can, however, also derive from increased root age with soil depth (Gaudinski et al., 2001). Overall, OC quality indices show that fractions are more similar in the uppermost than in deeper soil layers, suggesting a stronger decoupling of fractions and their genesis at depth. 


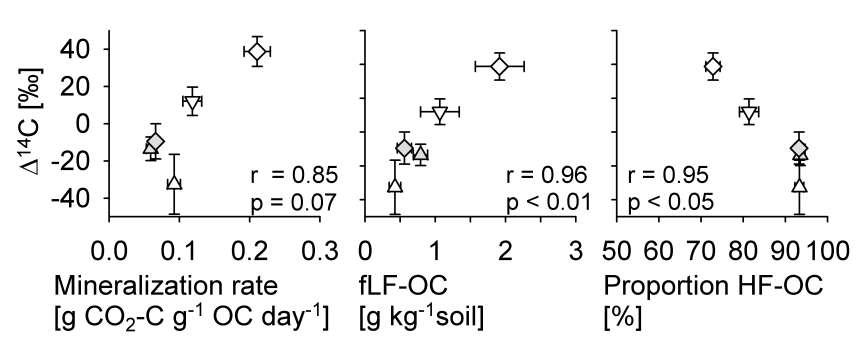

Fig. 12. Relation between average $\Delta^{14} \mathrm{C}$ and specific mineralization rates per $\mathrm{g} \mathrm{OC}$, amount of $\mathrm{OC}$ with the $\mathrm{fLF}$, and the proportion of HF (heavy fraction)-OC at $10-20 \mathrm{~cm}$ soil depth (only undisturbed sites Hainich, Hesse, Sorø, Bugac, Laqueuille containing no fossil C).

\subsection{Factors influencing the amount and depth distributions of LF-OC}

Jobbagy and Jackson (2000) showed that vegetation type influences depth distributions of total soil OC through differences in C allocation to roots. Similar to the present study, they observed that less roots are concentrated in upper soil layers of deciduous forests ( $60 \%$ of all roots to $60 \mathrm{~cm}$ depth) than of temperate grasslands (72\%). The close correspondence between depth distributions of roots and LF-OC at our study sites suggests that root litter input shapes the depth profiles of LF-OC. Land use changes going along with changes in the rooting systems will therefore affect the depth distribution of LF-OC.

The correlation between the root mass and $\mathrm{OC}$ in density fractions suggests that root mass is a good indicator for litter input across sites. However, relative to root mass, more LF-OC was found in soils of the coniferous forests than in soils of the non-coniferous sites included in our study. Large LF-OC contents in coniferous forests have been observed before (e.g., by Crow et al., 2007; Kaiser et al., 2002; Laganière et al., 2011), and may reflect the additional influence of environmental constraints, such as soil acidity, or reduced litter quality (wide OC-to-TN ratio in conifers). At the sandy semiarid grassland site Bugac in Hungary, summer drought possibly causes slowing decomposition rates, thus, leading to larger LF-OC contents. Increasing LF-OC with increasing sand contents indicates overall greater importance of LF-OC for OC storage at sites with limited sorption capacity of the HF.

Tillage influences the depth profiles of OC with the LF by homogenizing soil material in the plough layer. The destruction of soil structure by tillage, subjecting formerly occluded OC to microbial degradation, has been assumed to be the reason for the reduced contributions of LF to total OC stocks in croplands compared to forests or grasslands (Alvarez et al., 1998; Balesdent et al., 2000; John et al., 2005; Roscoe and Buurman, 2003). Grubber-tillage before sampling caused mixing of fresh harvest residues into the upper soil layer at the sites Gebesee and Grignon. Accordingly, soil

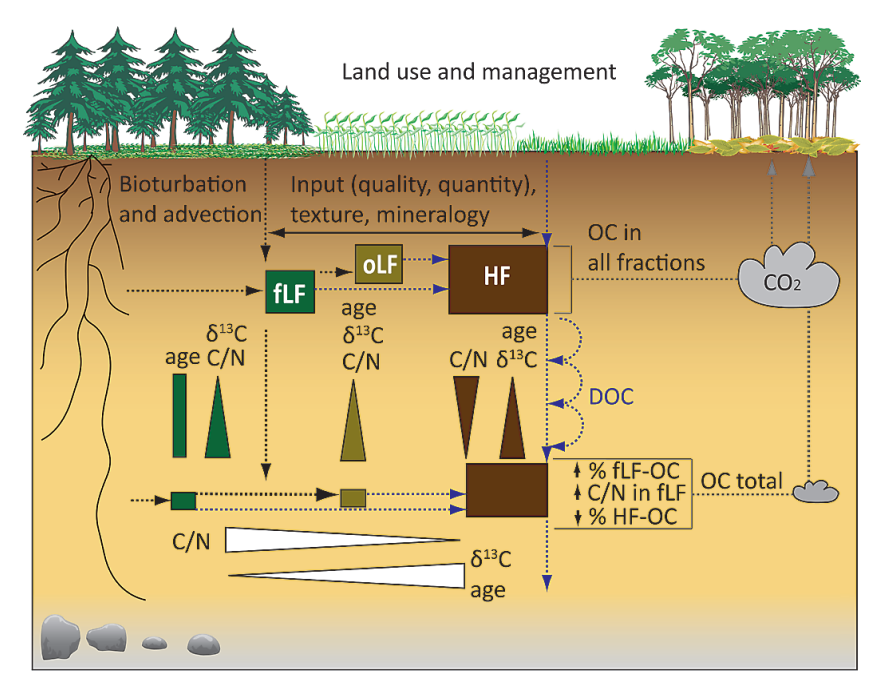

Fig. 13. Summary of characteristics of density fractions in topsoil and subsoil layers and their relation to soil respiration (fLF: free light fraction, oLF: occluded light fraction, HF: heavy fraction, OC: OC concentration).

management, but also sampling time, influence estimates of the contribution of LF to total OC of cropland soils.

Besides litter, also variable amounts of charred or fossil C can modify the quality and ${ }^{14} \mathrm{C}$-age of LF-OC (Gregorich et al., 2006; Marschner et al., 2008; Wagai et al., 2009). Fossil $\mathrm{C}$ contributed to LF-OC at three out of our 12 study sites. Deposits from industrial C, as observed for example by Rethemeyer et al. (2004), accumulate in surface layers. However, contributions of old OC were larger in deeper soil layers at the three respective study sites. Rumpel and Kögel-Knabner (2011) pointed out that substrate-derived geogenic $\mathrm{C}$ can influence bulk ${ }^{14} \mathrm{C}$ values of subsoils. Soils of the sites Carlow and Easter Bush both developed on Carboniferous sedimentary rocks, and Grignon on loess over tertiary or cretaceous sedimentary rocks. Small pieces of coal were observed during sample preparation at Easter Bush and Grignon, and coal is also mined in the area around Easter Bush. As coal densities are within the density of the LF-OC, we assume that coal derived from the sedimentary parent material contributed to LF-OC at these study sites. Due to overlapping densities, it is probably not possible to separate this fossil OC from recent plant material using density fractionation. Possible contributions of fossil $\mathrm{C}$ derived from the parent material therefore need to be considered for soils on sedimentary parent material.

\subsection{Factors controlling the amount and depth distribution of HF-OC}

The formation of HF-OC involves sorption of OC to mineral surfaces. Our study confirmed previous observations that secondary hydrous $\mathrm{Fe}$ and $\mathrm{Al}$ phases are generally more important to $\mathrm{OC}$ accumulation in the HF than total clay 
content (Kaiser and Guggenberger, 2000; Kögel-Knabner et al., 2008; Torn et al., 1997). The OC-loading of minerals typically decreased with soil depth at our study sites. For example, the ratio of HF-OC to $\mathrm{Al}_{\mathrm{o}}+\mathrm{Fe}_{\mathrm{d}}$ declined by roughly $60 \%$ from the $0-5 \mathrm{~cm}$ to the $10-20 \mathrm{~cm}$ soil layer at the deciduous forest sites. Little to no relation between mineral indicators and OC can be expected when available binding sites at mineral surfaces are not occupied. This could be one explanation for weaker or no correlation between HF-OC and pedogenic oxides across sites for deeper soil layers.

Soluble decomposition products of LF-OC are a possible source for HF-OC. Positive relations between $\Delta^{14} \mathrm{C}$ of fLFOC and OLF-OC, and between OLF-OC and HF-OC indicate that formation and turnover of these fractions are not entirely independent of each other in the topsoil. Several recent studies highlight the role of roots for soil OC storage (Bird and Torn, 2006; Rasse et al., 2005; Sanaullah et al., 2011), which is indicated by the relation between root mass and HF-OC in the uppermost soil layer in the present study. Direct transfer of OC from the LF to the HF would result in roughly similar depth distributions of both fractions. However, subsoils had much more HF- than LF-OC, especially at the grassland sites (Fig. 5).

Several studies suggested that transport of DOC contributes significantly to OC accumulation in subsoils (Baisden and Parfitt, 2007; Kaiser and Kalbitz, 2012; Kalbitz and Kaiser, 2008; Sanderman and Amundson, 2008). Different sorption rates of younger DOC from overlying horizons to minerals in subsoils should be reflected in different depth profiles of the $\Delta^{14} \mathrm{C}$ of the HF. The $\Delta{ }^{14} \mathrm{C}$ of the HF at our study sites declined almost linearly with soil depth down to the $30-40 \mathrm{~cm}$ layer at undisturbed sites but slopes of the decline varied among sites (see example in Fig. 14 and Supplement Fig. A1). These slopes were positively correlated with the DOC fluxes measured by Kindler et al. (2011) at some of the study sites, and with the amounts of dissolved OC sorbed in the subsoil (Fig. 14). A small increase in radiocarbon contents with depth at sites with large fluxes and large sorption of DOC indicates an overall faster transport of younger OC into deeper soil layers. This is supported by the negative relation between soil $\mathrm{pH}$ and the slopes of the $\Delta^{14} \mathrm{C}$ depth decline, which points at deeper penetration of younger $\mathrm{OC}$ with the larger fluxes of dissolved OC in acidic soils (Fig. 14). Accordingly, the $\Delta^{14} \mathrm{C}$-gradient of HF-OC in the upper parts of soil profiles can be an indicator for transport rates of DOC.

As suggested by Masiello et al. (2004), our study shows, based on independent measures, that DOC is relevant to the formation of HF-OC in subsoils, irrespective of texture, acidity, or land use type. The $\Delta^{14} \mathrm{C}$ values of the $\mathrm{HF}$ of subsoils, therefore, reflect not only $\mathrm{OC}$ turnover in the given layer but the entire residence time of OC in the soil profile.

\subsection{Link between organic carbon stability and density fractions in topsoils and subsoils}

The combination of specific mineralization rates from incubations and $\Delta^{14} \mathrm{C}$ values as indicators for OC stability was useful to overcome limitations of each approach. Incubations give potential mineralization rates of labile $\mathrm{OC}$ fractions and exclude interactions between plants and soil. Still, Kutsch et al. (2010) showed for the Hainich site that heterotrophic soil respiration rates measured in the field compare well to those obtained in our laboratory incubations, after correcting for soil temperature and moisture. The $\Delta^{14} \mathrm{C}$ of soils is one of the most important tracers for cycling of soil $\mathrm{C}$ under field conditions on timescales of years to decades (Torn et al., 2009; Trumbore, 2009). Direct correlations between specific mineralization rates and $\Delta^{14} \mathrm{C}$ values can only be expected for OC fractions with homogenous turnover times (Torn et al., 2009). This could be one reason why we did not find close correlations between $\Delta^{14} \mathrm{C}$ data and incubation results for the uppermost soil layer.

Modern $\Delta^{14} \mathrm{C}$ values of all fractions in the uppermost soil layer of sites not containing fossil $\mathrm{C}$, and correlations between $\mathrm{CO}_{2}$-release rates and $\mathrm{OC}$ in all three density fractions suggest that $\mathrm{OC}$ in all three fractions turns over fast enough to contribute significantly to mineralization rates. Nevertheless, stronger responses of mineralization rates to contents of fLFOC than of HF-OC hint at fLF-OC being more bioavailable than HF-OC. Also, lower $\Delta^{14} \mathrm{C}$ of the HF than of the fLF indicate that part of HF-OC in topsoils has longer turnover times, and thus, is stabilized against degradation.

Declining specific mineralization rates and increasing mean residence times of $\mathrm{OC}$ with soil depth suggest a general increase in the stability of OC with soil depth across sites. Similar results have been obtained by Fang and Moncrieff (2005), Lomander et al. (1998) and in studies summarized in Kögel-Knabner et al. (2008). Especially the mean residence time of HF-OC strongly increased with soil depth, while fLF-OC mostly remained modern (see e.g., studies in Kögel-Knabner et al., 2008). Reduced bioavailability of HF-OC at depth is supported by the negative correlation between $\mathrm{OC}$-normalized $\mathrm{CO}_{2}$ release and the proportion of OC with the HF, which is significant across sites, except for the uppermost soil layer. One explanation for stronger protection of mineral-associated OC in deeper soil layers is stronger sorption of OC to mineral surfaces with smaller OM loading (Guggenberger and Kaiser, 2003; Kögel-Knabner et al., 2008). This causes longer residence times of $\mathrm{OC}$ at mineral surfaces because of reducing the desorption, which is a prerequisite for degradation of mineralbound OC (Guggenberger and Kaiser, 2003; Jones and Edwards, 1998; Kaiser et al., 2007; Kögel-Knabner et al., 2008; Mikutta et al., 2007). The positive correlation between OCnormalized $\mathrm{CO}_{2}$-release rates and bulk sample $\Delta^{14} \mathrm{C}$, and the negative correlation between bulk sample $\Delta^{14} \mathrm{C}$ and the contribution of HF to total OC at $10-20 \mathrm{~cm}$ depth, confirms 


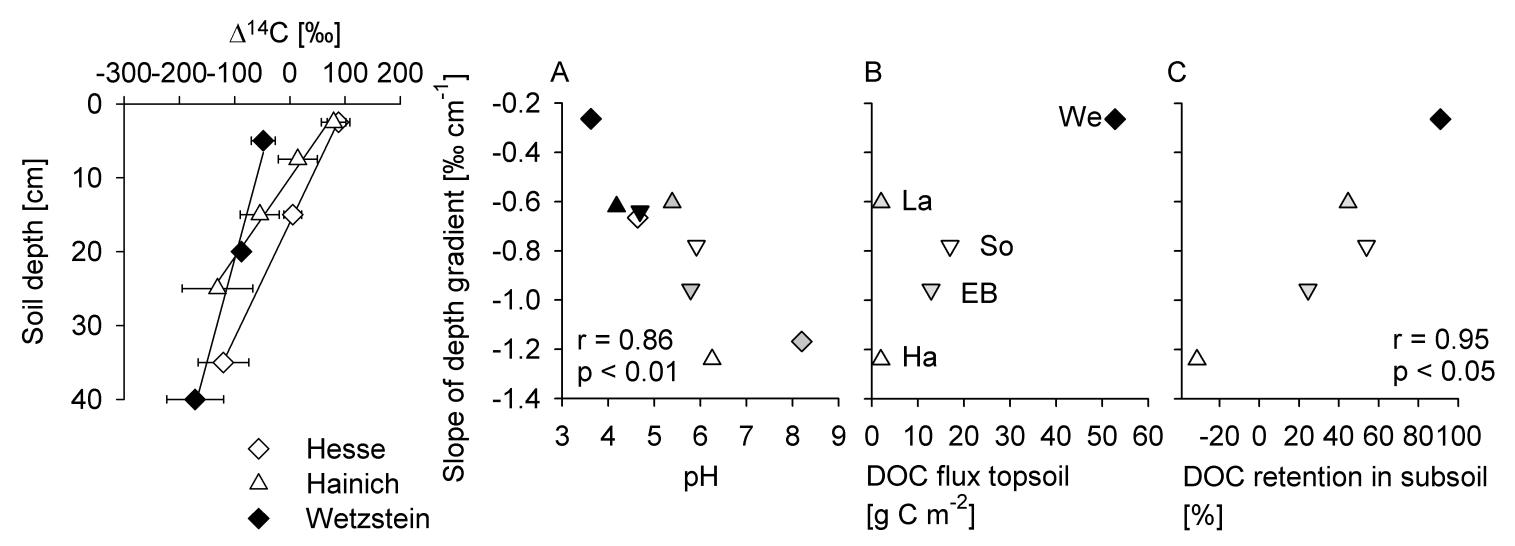

Fig. 14. Relation between the slope of the decline of $\mathrm{HF} \Delta^{14} \mathrm{C}$ with soil depth and (A) $\mathrm{pH}$ values of the upper $30 \mathrm{~cm}$ of the soil, (B) dissolved OC fluxes in the topsoil (values taken from Kindler et al., 2011), and (C) OC retention in the subsoil (values taken from Kindler et al., 2011). (La: Laqueuille, We: Wetzstein, So: Sorø, EB: Easter Bush, Ha: Hainich, black: coniferous forest, dark grey: croplands, light gray: grasslands, white: deciduous forests.)

independently slower turnover of OC in deeper soil layers with more OC in the HF.

In the case of HF-OC being less bioavailable at depth, LF-OC would become even more relevant as an energy and nutrient source in deeper soil layers. This is in agreement with the higher $\Delta^{14} \mathrm{C}$ values and explains the positive relation between OC-normalized $\mathrm{CO}_{2}$ release, fLF-OC, and the proportion of OC with fLF for deeper soil layers. Greater OC-normalized $\mathrm{CO}_{2}$ release at sites with large OC-to-TN ratios in the fLF suggests that microbial growth in subsoils is $\mathrm{N}$-limited, so that meeting $\mathrm{N}$ demands requires complete processing of the fLF. This is supported by increasing OC-to-TN ratios of fLF-OC with depth at most sites. The increase in TN relative to OC in HF with depth hints at unequal nutrient bioavailability in the two fractions, possibly because of better protection of $\mathrm{OM}$ in the HF, or large contributions of biologically unavailable mineral $\mathrm{N}$ in subsoils. Accordingly, the amount of OC and the OC-to-TN ratio of the fLF were good indicators of OC turnover in subsoils. As absolute mineralization rates in subsoils were linked to total OC, which was dominated by HF-OC, a portion of that fraction seems to be active throughout the profile. This is in line with previous findings by Swanston et al. (2005), Tan et al. (2007) and Trumbore (1993).

\subsection{The unresolved role of the occluded light fraction}

Differences in OC-to-TN ratios and $\delta^{13} \mathrm{C}$ values between $\mathrm{fLF}$ and oLF were not consistent enough to support the idea of the oLF being generally more degraded than the fLF. Overall, oLF rather resembled fLF than $\mathrm{HF}$ in terms of $\delta^{13} \mathrm{C}$ and OC-to-TN ratio. It has an intermediate ${ }^{14} \mathrm{C}$-content, ranging between that of the fLF and the HF. This hints at some stabilization of LF-OC by occlusion within aggregates, especially in deeper layers, as suggested by Rasmussen et al. (2005) and Salomé et al. (2009). The rather small portion of OC with the oLF as compared to HF-OC might explain why no correlation between specific respiration rates and oLF-OC was found. Also, it was not possible to identify single factors or processes explaining oLF-OC contents across sites, possibly due to variable contributions of selectively preserved organic material with large OC-to-TN ratios (like charred material), as suggested by Wagai et al. (2009). In addition, methodological problems must be considered when attempting to distinguish between "aggregate-protected" and "unprotected" organic matter. For example, larger organic particles, such as degrading roots, may be partially within aggregates but also partially without. In addition, sonication treatments, while optimized for aggregate disruption, have also been shown to cause redistribution of OC across fractions by differential dispersion of HF material (Kaiser and Guggenberger, 2007). For example, the large amount of oLF-OC in the sandy soil at Le Bray (Supplement Fig. A1) likely was not from within aggregates (the soils are weakly aggregated) but originates from disruption of weak organic-sand associations upon sonication. Characterizing oLF-OC is therefore more difficult than the fully unprotected fLF-OC and the mineralassociated OC.

\section{Summary}

The distribution of OC over density fractions determined the overall stability of subsoil OC for all types of vegetation, land use, and soil. The combined application of density fractionation, laboratory incubations, and isotope analyses across a range of sites mostly confirmed concepts of OC stability in soils. The following conclusions and implications arise from our study: 


\section{Sources of LF-OC and HF-OC}

Root distribution is a good predictor for LF-OC along the soil profile. Coal from sedimentary parent material and charcoal can also contribute to LF-OC at certain sites, strongly impacting $\Delta^{14} \mathrm{C}$ values. In subsoils, the young $\mathrm{LF}-\mathrm{OC}$ is mineralised preferentially, thus does not contribute much to $\mathrm{HF}$ OC. Instead, slow downward migration of DOC is a more important source of HF-OC in subsoils, contributing to the greater difference of isotopic signatures and $\mathrm{OC}$-to- $\mathrm{TN}$ ratios between fractions in deeper soil layers.

2. Association with minerals provides protection against mineralization

Our study confirmed association with minerals as the single most important OC stabilization mechanism in the soil. The separation into a rather active fLF-OC and a largely inactive HF-OC was more pronounced in deeper soil layers than in the topsoil, probably due to greater stability of HF-OC at depth. Nevertheless, a small component of the HF-OC, likely with compounds weakly attached, contributed to $\mathrm{CO}_{2}$ release in incubations, as already observed in some previous studies. In topsoils, HF-associated organic matter might be of more transient nature, prone to steady replacement by freshly produced reactive organic compounds. Aged DOC displaced from topsoils may then migrate downwards, forming the HFOC of subsoils.

3. Occlusion within aggregates increases the longevity of LF-OC throughout the soil profile

Occluded LF-OC often has an intermediate ${ }^{14} \mathrm{C}$ signature, between that of fLF-OC and HF-OC. The heterogeneous composition of oLF-OC does not allow for ascribing the reason for greater stability either to spatial separation from decomposers or the presence of refractory or charred compounds. Since far less of the total OC is found with the oLF than with the HF, binding to minerals is the more relevant stabilization mechanism, especially in subsoils.

\section{4. fLF-OC fuels biological activity}

The OC and the OC-to-TN ratio of the fLF were universal predictors of the biodegradability of soil OC in top- as well as in subsoils. Enhanced root litter input will promote biological activity and probably turnover of a larger OC stock, as suggested by Bird et al. (2011). The close correlation between fLF-OC and the $\mathrm{CO}_{2}$-release per $\mathrm{g}$ soil $\mathrm{OC}$ indicates that decomposition was mostly independent of site-specific differences in root litter quality or mineral composition in deeper soil layers.

\section{Limited OC storage capacity in soils}

One consequence of binding to minerals being the most important stabilizing process in soils is that long-term soil OC storage is finite. This is supported by greater shares of LF-OC in soils with small sorption capacity for OC of minerals. Unless other environmental constraints hamper decomposition, the OC storage capacity of soils will depend on the availability of binding sites and, accordingly, on the soil's mineral composition and depth.

\section{Interpretation of ${ }^{14} \mathrm{C}$ data and modelling of $\mathrm{OC}$ turnover}

Conversion of $\Delta^{14} \mathrm{C}$ values of density fractions in a given soil layer into turnover rates needs to consider: (1) possible contributions of fossil $\mathrm{C}$, either of industrial sources or inherited by the parent material; (2) transfer of OC between fractions; (3) OC transport along the soil profile; and (4) lags between the time of fixation and the time OC enters the soil (Gaudinski et al., 2001; Sah et al., 2011; Trumbore, 2009). This requires a more complex modelling approach and further constraints, such as litter input, and is beyond the scope of this study, thus, remaining a future task.

\section{Supplementary material related to this article is available online at: http://www.biogeosciences.net/10/ 1675/2013/bg-10-1675-2013-supplement.pdf.}

Acknowledgements. The study was funded by the European Union. We are grateful to Matthias Grabe, Marco Pöhlmann, and Gerlinde Hardt for their help with soil sampling, preparation, and fractionation. We thank the Institute of Geosciences of the University Halle and the Centre for Environmental Research for the uncomplicated use of the laboratories. We would further like to thank the central facilities departments Routine Measurements and Analyses (Roma), and ${ }^{14} \mathrm{C}$ Analytik, both Max-Planck Institute for Biogeochemistry. We thank Susan Trumbore for helpful discussions and comments on an earlier version of this manuscript. Finally, we thank all site managers for their support during sampling and with site-related questions.

The service charges for this open access publication have been covered by the Max Planck Society.

Edited by: J.-A. Subke

\section{References}

Alvarez, C. R., Alvarez, R., Grigera, S., and Lavado, R. S.: Associations between organic matter fractions and the active soil microbial biomass, Soil Biol. Biochem., 30, 767-773, 1998.

Alvarez, R. and Alvarez, C. R.: Soil organic matter pools and their associations with carbon mineralization kinetics, Soil Sci. Soc. Am. J., 64, 184-189, 2000.

Baisden, W. T. and Parfitt, R. L.: Bomb ${ }^{14} \mathrm{C}$ enrichment indicates decadal C pool in deep soil?, Biogeochemistry, 85, 59-68, 2007.

Balesdent, J, Chenu, C., and Balabane, M.: Relationship of soil organic matter dynamics to physical protection and tillage, Soil Till. Res., 53, 215-230, 2000. 
Bird, J. A. and Torn, M. S.: Fine roots vs. Needles: A comparison of ${ }^{13} \mathrm{C}$ and ${ }^{15} \mathrm{~N}$ dynamics in a ponderosa pine forest soil, Biogeochemistry, 79, 361-382, 2006.

Bird, J. A., Herman, D. J., and Firestone, M. K.: Rhizosphere priming of soil organic matter by bacterial groups in a grassland soil, Soil Biol. Biochem., 43, 718-725, 2011.

Boström, B., Comstedt, D., and Ekblad, A.: Isotope fractionation and ${ }^{13} \mathrm{C}$ enrichment in soil profiles during the decomposition of soil organic matter, Oecologia, 153, 89-98, 2007.

Cerli, C., Celi, L., Kalbitz, K., Guggenberger, G., and Kaiser, K.: Separation of light and heavy organic matter fractions in soil - Testing for proper density cut-off and dispersion level, Geoderma, 170, 403-416, 2012.

Crow, S. E., Swanston, C. W., Lajtha, K., Brooks, J. R., and Keirstead, H.: Density fractionation of forest soils: methodological questions and interpretation of incubation results and turnover time in an ecosystem context, Biogeochemistry, 85, 6990, 2007.

Don, A., Scholten, T., and Schulze, E. D.: Conversion of cropland into grassland: Implications for soil organic-carbon stocks in two soils with different texture, J. Plant Nutr. Soil Sc., 172, 53-62, 2009.

Dungait, J. A. J., Hopkins, D. W., Gregory, A. S., and Whitmore, A. P.: Soil organic matter turnover is governed by accessibility not recalcitrance, Glob. Change Biol., 18, 1781-1796, 2012.

Ehleringer, J. R., Buchmann, N., and Flanagan, L. B.: Carbon isotope ratios in belowground carbon cycle processes, Ecol. Appl., 10, 412-422, 2000.

Fang, C. M. and Moncrieff, J. B.: The variation of soil microbial respiration with depth in relation to soil carbon composition, Plant Soil, 268, 243-253, 2005.

Fontaine, S., Barot, S., Barre, P., Bdioui, N., Mary, B., and Rumpel, C.: Stability of organic carbon in deep soil layers controlled by fresh carbon supply, Nature, 450, 277-281, 2007.

Gärdenäs, A. I., Ågren, G. I., Bird, J. A., Clarholm, M., Hallin, S., Ineson, P., Kätterer, T., Knicker, H., Nilsson, S. I., Näsholm, T., Ogle, S., Paustian, K., Persson, T., and Stendahl, J.: Knowledge gaps in soil carbon and nitrogen interactions - From molecular to global scale, Soil Biol. Biochem., 43, 702-717, 2011.

Gaudinski, J. B., Trumbore, S. E., Davidson, E. A., Cook, A. C., Markewitz, D., and Richter, D. D.: The age of fine-root carbon in three forests of the eastern United States measured by radiocarbon, Oecologia, 129, 420-429, 2001.

Genenger, M., Jaeggi, M., Siegwolf, R., Chalot, M., Frossard, E., and Brunner, I.: Rapid N-15 uptake and metabolism in fine roots of Norway spruce, Trees-Struct. Funct., 17, 144-152, 2003.

Golchin, A., Oades, J. M., Skjemstad, J. O., and Clarke, P.: Study of Free and Occluded Particulate Organic-Matter in Soils by SolidState ${ }^{13} \mathrm{C}$ CP/MAS NMR-Spectroscopy and Scanning ElectronMicroscopy, Aust. J. Soil Res., 32, 285-309, 1994.

Göransson, H., Fransson, A. M., and Jonsson-Belyazid, U.: Do oaks have different strategies for uptake of $\mathrm{N}, \mathrm{K}$ and $\mathrm{P}$ depending on soil depth?, Plant Soil, 297, 119-125, 2007.

Gregorich, E. G., Beare, M. H., McKim, U. F., and Skjemstad, J. O.: Chemical and biological characteristics of physically uncomplexed organic matter, Soil Sci. Soc. Am. J., 70, 975-985, 2006.

Guggenberger, G. and Kaiser, K.: Dissolved organic matter in soil: challenging the paradigm of sorptive preservation, Geoderma, $113,293-310,2003$
Harrison, R. B., Adams, A. B., Licata, C., Flaming, B., Wagoner, G. L., Carpenter, P., and Vance, E. D.: Quantifying deep-soil and coarse-soil fractions: Avoiding sampling bias, Soil Sci. Soc. Am. J., 67, 1602-1606, 2003.

Hassink, J.: Density fractions of soil macroorganic matter and microbial biomass as predictors of C-mineralization and $\mathrm{N}$ mineralization, Soil Biol. Biochem., 27, 1099-1108, 1995.

Holmgren, G. G.: A rapid citrate-dithionite extractable iron procedure, Soil Science Society of America Proceedings, 31, 210-211, 1967.

Janzen, H. H., Campbell, C. A., Brandt, S. A., Lafond, G. P., and Townleysmith, L.: Light-fraction organic-matter in soils from long-term crop rotations, Soil Sci. Soc. Am. J., 56, 1799-1806, 1992.

Jobbagy, E. G. and Jackson, R. B.: The vertical distribution of soil organic carbon and its relation to climate and vegetation, Ecol. Appl., 10, 423-436, 2000.

John, B., Yamashita, T., Ludwig, B., and Flessa, H.: Storage of organic carbon in aggregate and density fractions of silty soils under different types of land use, Geoderma, 128, 63-79, 2005.

Jones, D. L. and Edwards, A. C.: Influence of sorption on the biological utilization of two simple carbon substrates, Soil Biol. Biochem., 30, 1895-1902, 1998.

Kaiser, K. and Guggenberger, G.: The role of DOM sorption to mineral surfaces in the preservation of organic matter in soils, Org. Geochem., 31, 711-725, 2000.

Kaiser, K. and Guggenberger, G.: Distribution of hydrous aluminium and iron over density fractions depends on organic matter load and ultrasonic dispersion, Geoderma, 140, 140-146, 2007.

Kaiser, K. and Kalbitz, K.: Cycling downwards - dissolved organic matter in soils, Soil Biol. Biochem., 52, 29-32, 2012.

Kalbitz, K. and Kaiser, K.: Contribution of dissolved organic matter to carbon storage in forest mineral soils, J. Plant Nutr. Soil Sc., 171, 52-60, 2008.

Kaiser, K., Eusterhues, K., Rumpel, C., Guggenberger, G., and Kogel-Knabner, I.: Stabilization of organic matter by soil minerals - investigations of density and particle-size fractions from two acid forest soils, J. Plant Nutr. Soil Sc., 165, 451-459, 2002.

Kaiser, K., Mikutta, R., and Guggenberger, G.: Increased stability of organic matter sorbed to ferrihydrite and goethite on aging, Soil Sci. Soc. Am. J., 71, 711-719, 2007.

Kindler, R., Siemens, J., Kaiser, K., Walmsley, D. C., Bernhofer, C., Buchmann, N., Cellier, P., Eugster, W., Gleixner, G., Grunwald, T., Heim, A., Ibrom, A., Jones, S. K., Jones, M., Klumpp, K., Kutsch, W., Larsen, K. S., Lehuger, S., Loubet, B., McKenzie, R., Moors, E., Osborne, B., Pilegaard, K., Rebmann, C., Saunders, M., Schmidt, M. W. I., Schrumpf, M., Seyfferth, J., Skiba, U., Soussana, J. F., Sutton, M. A., Tefs, C., Vowinckel, B., Zeeman, M. J., and Kaupenjohann, M.: Dissolved carbon leaching from soil is a crucial component of the net ecosystem carbon balance, Glob. Change Biol., 17, 1167-1185, 2011.

Kögel-Knabner, I., Guggenberger, G., Kleber, M., Kandeler, E., Kalbitz, K., Scheu, S., Eusterhues, K., and Leinweber, P. Organo-mineral associations in temperate soils: Integrating biology, mineralogy, and organic matter chemistry, J. Plant Nutr. Soil Sc., 171, 61-82, 2008.

Kutsch, W., Persson, T., Schrumpf, M., Moyano, F. E., Mund, M., Andersson, S., and Schulze, E. D.: Heterotrophic soil respira- 
tion and soil carbon dynamics in the deciduous Hainich forest obtained by three approaches, Biogeochemistry, 100, 167-183, 2010.

Laganière, J., Angers, D. A., Pare, D., Bergeron, Y., and Chen, H. Y. H.: Black spruce soils accumulate more uncomplexed organic matter than aspen soils, Soil Sci. Soc. Am. J., 75, 1125-1132, 2011.

Lomander, A., Kätterer, T., and Andrén, O.: Carbon dioxide evolution from top- and subsoil as affected by moisture and constant and fluctuating temperature, Soil Biol. Biochem., 30, $2017-$ 2022, 1998.

Marschner, B., Brodowski, S., Dreves, A., Gleixner, G., Gude, A., Grootes, P. M., Hamer, U., Heim, A., Jandl, G., Ji, R., Kaiser, K., Kalbitz, K., Kramer, C., Leinweber, P., Rethemeyer, J., Schaeffer, A., Schmidt, M. W. I., Schwark, L., and Wiesenberg, G. L. B.: How relevant is recalcitrance for the stabilization of organic matter in soils?, J. Plant Nutr. Soil Sc., 171, 91-110, 2008.

Masiello, C. A., Chadwick, O. A., Southon, J., Torn, M. S., and Harden, J. W.: Weathering controls on mechanisms of carbon storage in grassland soils, Glob. Biogeochem. Cy., 18,GB4023, doi:10.1029/2004GB002219, 2004.

Melillo, J. M., Aber, J. D., Linkins, A. E., Ricca, A., Fry, B., and Nadelhoffer, K. J.: Carbon and nitrogen dynamics along the decay continuum - plant litter to soil organic-matter, Plant Soil, 115, 189-198, 1989.

Michalzik, B., Tipping, E., Mulder, J., Lancho, J. F. G., Matzner, E., Bryant, C. L., Clarke, N., Lofts, S., and Esteban, M. A. V.: Modelling the production and transport of dissolved organic carbon in forest soils, Biogeochemistry, 66, 241-264, 2003.

Mikutta, R., Kleber, M., Torn, M. S., and Jahn, R.: Stabilization of soil organic matter: Association with minerals or chemical recalcitrance?, Biogeochemistry, 77, 25-56, 2006.

Mikutta, R., Mikutta, C., Kalbitz, K., Scheel, T., Kaiser, K., and Jahn, R.: Biodegradation of forest floor organic matter bound to minerals via different binding mechanisms, Geochim. Cosmochim. Ac., 71, 2569-2590, 2007.

Nieder, R., Benbi, D. K., and Scherer, H. W.: Fixation and defixation of ammonium in soils: a review, Biol. Fert. Soils, 47, 1-14, 2011.

Peltoniemi, M., Thurig, E., Ogle, S., Palosuo, T., Schrumpf, M., Wutzler, T., Butterbach-Bahl, K., Chertov, O., Komarov, A., Mikhailov, A., Gardenas, A., Perry, C., Liski, J., Smith, P., and Makipaa, R.: Models in country scale carbon accounting of forest soils, Silva Fennica, 41, 575-602, 2007.

Persson, T. and Wirén, A.: Effects of experimental acidification on $\mathrm{C}$ and $\mathrm{N}$ mineralization in forest soils, Agr. Ecosyst. Environ., 47, 159-174, 1993.

Persson, T., Lundkvist, H., Wirérn, A., Hyvönen, R., and Wessén, B.: Effects of acidification and liming on carbon and nitrogen mineralization and soil organisms in mor humus, Water Air Soil Pollut., 45, 76-96, 1989.

Poirier, N., Sohi, S. P., Gaunt, J. L., Mahieu, N., Randall, E. W., Powlson, D. S., and Evershed, R. P.: The chemical composition of measurable soil organic matter pools, Org. Geochem., 36, 1174-1189, 2005.

Ramsey, C. B.: Radiocarbon calibration and analysis of stratigraphy: The OxCal program, Radiocarbon, 37, 425-430, 1995.

Rasmussen, C., Torn, M. S., and Southard, R. J.: Mineral assemblage and aggregates control carbon dynamics in a California conifer forest, Soil Sci. Soc. Am. J., 69, 1711-1721, 2005.
Rasse, D. P., Rumpel, C., and Dignac, M. F.: Is soil carbon mostly root carbon? Mechanisms for a specific stabilisation, Plant Soil, 269, 341-356, 2005.

Rethemeyer, J., Grootes, P. M., Bruhn, F., Andersen, N., Nadeau, M. J., Kramer, C., and Gleixner, G.: Age heterogeneity of soil organic matter, Nuclear Instruments \& Methods in Physics Research Section B-Beam Interactions with Materials and Atoms, 223, 521-527, 2004.

Roscoe, R. and Buurman, P.: Tillage effects on soil organic matter in density fractions of a Cerrado Oxisol, Soil Till. Res., 70, 107119, 2003.

Rumpel, C. and Kögel-Knabner, I.: Deep soil organic matter-a key but poorly understood component of terrestrial C cycle, Plant Soil, 338, 143-158, 2011.

Sah, S. P., Jungner, H., Oinonen, M., Kukkola, M., and Helmisaari, H. S.: Does the age of fine root carbon indicate the age of fine roots in boreal forests?, Biogeochemistry, 104, 91-102, 2011.

Salomé, C., Nunan, N., Pouteau, V., Lerch, T. Z., and Chenu, C.: Carbon dynamics in topsoil and in subsoil may be controlled by different regulatory mechanisms, Glob. Change Biol., 16, 416426, 2009.

Sanaullah, M., Chabbi, A., Leifeld, J., Bardoux, G., Billou, D., and Rumpel, C.: Decomposition and stabilization of root litter in topand subsoil horizons: what is the difference?, Plant Soil, 338, 127-141, 2011.

Sanderman, J. and Amundson, R.: A comparative study of dissolved organic carbon transport and stabilization in California forest and grassland soils, Biogeochemistry, 89, 309-327, 2008.

Schlichting, E. and Blume, H. P.: Bodenkundliches Praktikum, Verlag Paul Paney, Hamburg, 1964.

Schmidt, M. W. I., Rumpel, C., and Kögel-Knabner, I.: Particle size fractionation of soil containing coal and combusted particles, Eur. J. Soil Sci., 50, 515-522, 1999.

Schmidt, M. W. I., Torn, M. S., Abiven, S., Dittmar, T., Guggenberger, G., Janssens, I. A., Kleber, M., Kögel-Knabner, I., Lehmann, J., Manning, D. A. C., Nannipieri, P., Rasse, D. P., Weiner, S., and Trumbore, S. E.: Persistence of soil organic matter as an ecosystem property, Nature, 478, 49-56, 2011.

Schrumpf, M., Schulze, E. D., Kaiser, K., and Schumacher, J.: How accurately can soil organic carbon stocks and stock changes be quantified by soil inventories?, Biogeosciences, 8, 1193-1212, doi:10.5194/bg-8-1193-2011, 2011.

Schwertmann, U.: Differenzierung der Eisenoxide des Bodens durch Extraktion mit Ammoniumoxalat-Lösung, Zeitschrift für Pflanzenernährung, Düngung und Bodenkunde, 105, 194-202, 1964.

Six, J., Elliott, E. T., Paustian, K., and Doran, J. W.: Aggregation and soil organic matter accumulation in cultivated and native grassland soils, Soil Sci. Soc. Am. J., 62, 1367-1377, 1998.

Six, J., Schultz, P. A., Jastrow, J. D., and Merckx, R.: Recycling of sodium polytungstate used in soil organic matter studies, Soil Biol. Biochem., 31, 1193-1196, 1999.

Sohi, S. P., Mahieu, N., Arah, J. R. M., Powlson, D. S., Madari, B., and Gaunt, J. L.: A procedure for isolating soil organic matter fractions suitable for modeling, Soil Sci. Soc. Am. J., 65, 11211128, 2001.

Sohi, S. P., Mahieu, N., Powlson, D. S., Madari, B., Smittenberg, R. H., and Gaunt, J. L.: Investigating the chemical characteristics of soil organic matter fractions suitable for modeling, Soil Sci. Soc. 
Am. J., 69, 1248-1255, 2005.

Steinbeiss, S., Bessler, H., Engels, C., Temperton, V. M., Buchmann, N., Roscher, C., Kreutziger, Y., Baade, J., Habekost, M., and Gleixner, G.: Plant diversity positively affects short-term soil carbon storage in experimental grasslands, Glob. Change Biol., 14, 2937-2949, 2008.

Steinhof, A., Adamiec, G., Gleixner, G., van Klinken, G. J., and Wagner, T.: The new ${ }^{14} \mathrm{C}$ analysis laboratory in Jena, Germany, Radiocarbon, 46, 51-58, 2004.

Swanston, C. W., Caldwell, B. A., Homann, P. S., Ganio, L., and Sollins, P.: Carbon dynamics during a long-term incubation of separate and recombined density fractions from seven forest soils, Soil Biol. Biochem., 34, 1121-1130, 2002.

Swanston, C. W., Torn, M. S., Hanson, P. J., Southon, J. R., Garten, C. T., Hanlon, E. M., and Ganio, L.: Initial characterization of processes of soil carbon stabilization using forest stand-level radiocarbon enrichment, Geoderma, 128, 52-62, 2005.

Tan, Z., Lal, R., Owens, L., and Izaurralde, R. C.: Distribution of light and heavy fractions of soil organic carbon as related to land use and tillage practice, Soil Till. Res., 92, 53-59, 2007.

Torn, M. S., Trumbore, S. E., Chadwick, O. A., Vitousek, P. M., and Hendricks, D. M.: Mineral control of soil organic carbon storage and turnover, Nature, 389, 170-173, 1997.
Torn, M. S., Swanston, C. W., Castanha, C., and Trumbore, S. E.: Storage and turnover of organic matter in soils, in: BiophysicoChemical Processes Involving Natural Nonliving Organic Matter in Environmental Systems, edited by: Senesi, N., Xing, B., and Huang, P. M., John Wiley \& Sons, Inc, Hoboken, NJ, USA, 215 268, 2009.

Trumbore, S. E.: Comparison of Carbon Dynamics in Tropical and Temperate Soils Using Radiocarbon Measurements, Glob. Biogeochem. Cy., 7, 275-290, 1993.

Trumbore, S.: Radiocarbon and Soil Carbon Dynamics, Annu. Rev. Earth Planet. Sci., 37, 47-66, 2009.

Ugawa, S., Miura, S., Iwamoto, K., Kaneko, S., and Fukuda, K.: Vertical patterns of fine root biomass, morphology and nitrogen concentration in a subalpine fir-wave forest, Plant Soil, 335, 469478, 2010.

Wagai, R., Mayer, L. M., and Kitayama, K.: Nature of the "occluded" low-density fraction in soil organic matter studies: A critical review, Soil Sci. Plant Nutr., 55, 13-25, 2009.

Wander, M.: Soil organic matter fractions and their relevance to soil function, in: Soil Organic Matter in Sustainable Agriculture, edited by: Magdoff, F., and Weil, R. R., Advances in Agroecology, CRC Press Inc, Boca Raton, 67-102, 2004.

Werner, R. A. and Brand, W. A.: Referencing strategies and techniques in stable isotope ratio analysis, Rapid Commun. Mass Spectrom., 15, 501-519, 2001. 